\title{
Analysis of the interannual variability in satellite gravity solutions: detection of climate modes in water mass displacements across continents and oceans
}

Julia Pfeffer ( $\boldsymbol{\nabla}$ julia.pfeffer@magellium.fr )

Magellium https://orcid.org/0000-0002-3486-4793

Anny Cazenave

LEGOS: Laboratoire d'etudes en Geophysique et oceanographie spatiales

Anne Barnoud

Magellium

\section{Research Article}

Keywords: satellite gravity measurements, natural climate variability, climate modes

Posted Date: July 6th, 2021

DOl: https://doi.org/10.21203/rs.3.rs-177716/v1

License: (c) (i) This work is licensed under a Creative Commons Attribution 4.0 International License. Read Full License

Version of Record: A version of this preprint was published at Climate Dynamics on September 14th, 2021. See the published version at https://doi.org/10.1007/s00382-021-05953-z. 


\section{Abstract}

This study analyzes the interannual variability of the water mass transport measured by satellite gravity missions in regard to eight major climate modes known to influence the Earth's climate from regional to global scales. Using sparsity promoting techniques (i.e., LASSO), we automatically select the most relevant predictors of the climate variability among the eight candidates considered. The El NiñoSouthern Oscillation, Southern Annular Mode and Arctic Oscillation are shown to account for a large part the interannual variability of the water mass transport observed in extratropical ocean basins (up to $40 \%$ ) and shallow seas (up to $70 \%$ ). A combination of three Pacific and one Atlantic modes is needed to account for most (up to $60 \%$ ) of the interannual variability of the terrestrial water storage observed in the North Amazon, Parana and Zambezi basins. With our technique, the impact of climate modes on water mass changes can be tracked across distinct water reservoirs (oceans, continents and ice-covered regions) and we show that a combination of climate modes is necessary to explain at best the natural variability in water mass transport. The climate modes predictions based on LASSO inversions can be used to reduce the interannual variability in satellite gravity measurements and detect processes unrelated with the natural variability of climate but with similar spatio-temporal signatures. However, significant residuals in the satellite gravity measurements remain unexplained at interannual time scales and more complex models solving the water mass balance should be employed to better predict the variability of water mass distributions.

\section{Introduction}

Climate variability exerts profound influences on the water cycle, and therefore society. Over the past decade, increased evidence of an intensification of the water cycle has been reported (e.g., Eicker et al., 2016), leading to more frequent or more severe climate extremes, such as droughts, floods and wildfires (e.g., AghaKouchak et al., 2014; Turco et al., 2014; Yoon et al., 2015; Mora et al., 2018; Barichivich et al., 2018; Stevens-Rumann et al., 2018). Linking observed changes in climate extremes to anthropogenic greenhouse gases emissions is incredibly difficult due to the limited time-span of historical records and the aliasing with the natural climate variability, responsible for large fluctuations in the climate system over a broad range of time and space scales (e.g., Seneviratne et al., 2012; Easterling et al., 2016). In order to adapt to new risks and resources in a changing climate, it is necessary to develop tools able to characterize the natural variability of the climate system and pinpoint the mechanisms triggering changes observed in the climate system.

Climate modes synthesize emergent characteristics of the climate system in various regions of the world. These repeating patterns of the climate variability are usually identified through the statistical analysis (e.g., regional average, empirical orthogonal functions (EOF), principal component analysis) of one or several climate fields, such as sea surface temperature, air temperature, air pressure, sea level pressure, sea surface height, precipitation, wind speed and wind direction. Teleconnections, caused by the transport of moisture and energy through the atmosphere and the ocean, allow propagating the influence of regionally defined climate modes over large distances. Notoriously, the El Niño-Southern Oscillation 
(ENSO), observed by definition in the tropical Pacific, has global impacts on the Earth's climate, ecosystems and society (e.g., McPhaden et al., 2006; Capotondi et al., 2015). Similarly, the Atlantic Multidecadal Oscillation (AMO), has been reported to have nearly global influences on the climate system (e.g., Knight et al., 2006), including Amazonian (e.g., Kayano et al., 2016) or Sahelian (e.g., Mohino et al., 2011) rainfall, Atlantic hurricanes (e.g., Zhang \& Delworth, 2006), North American (e.g., Hu et al., 2011) and European summer climate (e.g., Zampieri et al., 2017). More and more frequently, it is found that a single climate mode is not sufficient to explain the major characteristics of regional climates, but that a combination of several modes, interacting with one another, is necessary to gain in climate predictability (e.g., Morrow et al., 2010; Li \& Wettstein, 2012; Kayano \& Capistrano, 2014; Petrick et al., 2014; Kundzewicz et al., 2019). Besides, it has been suggested that climate modes may not be stationary and that the spatial and temporal characteristics of climate modes, as well as their relationships with one another, may be evolving in a changing climate (e.g., Litzow et al., 2020).

The GRACE (Gravity Recovery and Climate Experiment) mission (e.g., Tapley et al., 2004), and its successor GRACE Follow-On (GRACE-FO) (e.g., Landerer et al., 2020), enabled global monitoring of the mass transport within the Earth's system, leading to unprecedented advances in our understanding of the global water cycle, ice and ocean mass variability in a changing climate (e.g., Tapley et al., 2019). Because they take into account all water bodies from the top of the atmosphere to deep aquifers, GRACE measurements are used to develop reliable indicators of the climate variability, including almostcontinuous monitoring of water shortage (e.g., Thomas et al., 2017) and/or excess (e.g., Chen et al., 2010) since 2002. Numerous studies have shown the influence of climate modes on GRACE and GRACEFO measurements, but are usually restricted to regional (e.g. Becker et al., 2011; Petrick et al., 2014; Zhang et al., 2015; Ndehedehe et al., 2017; Vissa et al., 2019; Xie et al., 2019) or continental (e.g. de Linage et al., 2013; Anyah et al., 2018; Ndehedehe \& Ferreira, 2020; Liu et al., 2020) scale studies, and/or to a limited subset of climate indices (e.g. Matsuo \& Heki, 2012; Bergmann \& Dobslaw, 2012; Landerer \& Volkov, 2013). Global analyses of the interannual variability of GRACE data are mostly focused on the impact of ENSO on terrestrial water storage (e.g., Phillips et al., 2012; Boening et al., 2012; Ni et al., 2018; Hamlington et al., 2019). Almost all studies previously cited acknowledge however the importance of the interactions and potential of aliasing between climate modes and recommend broader scale studies looking at the impact of several climate modes on GRACE and GRACE-FO measurements (e.g., Phillips et al., 2012; Petrick et al., 2014, Ni et al., 2018, Hamlington et al., 2019).

The objectives of this study are: (i) identify the climate modes driving significant water mass changes at interannual time-scales and, (ii) quantify the water mass changes due to climate modes. Correcting GRACE and GRACE-FO measurements for the contributions of climates modes could in turn unveil weaker signals masked by the natural variability of the climate system, such as deep Earth signals related to mass changes in the fluid core or at the core-mantle boundary (e.g., Mandea et al., 2015). To detect the climate modes responsible for water mass variations at interannual time scales, we carry a LASSO (Least Absolute Shrinkage and Selection Operator: Tibshirani, (1996)) regression of eight climate indices, namely MEI (Multivariate ENSO index), PDO (Pacific Decadal Oscillation), NPGO (North Pacific Gyre Oscillation), AMO, NAO (North Atlantic Oscillation), AO (Arctic Oscillation), SAM (Southern Annular Mode) 
and IOD (Indian Ocean Dipole). Indeed, it was recently suggested that the LASSO regularization can disentangle the contributions of various climate modes in historical reconstructions of steric sea levels to provide simple, easily interpretable models of the natural climate variability (Pfeffer et al., 2018). We test this method on GRACE and GRACE-FO satellite gravity measurements to estimate the contributions of major climate modes to the interannual variability of the water mass distributions. This analysis is the first global climate mode study to include both oceans and continents in the analysis of GRACE and GRACE-FO measurements.

\section{Principle, Data And Methods}

\subsection{Physical links between climate modes and the global water cycle}

The natural variability of the climate system gives rise to a vast array of dynamical climate modes, such as ENSO, AMO, NAO or SAM. Climate modes describe statistically emergent spatio-temporal patterns of regional climate variables, such as the sea/air temperature, precipitation, wind speed and sea/air pressure. Changes in temperature, precipitation and wind speed drive evaporation of water from the oceans and its transport through the atmosphere. During the particularly intense episode of La Niña in 2010/2011, the global mean sea level fell by about $5 \mathrm{~mm}$ due to the transport of water from the oceans to the continents, leading to particularly devastating flood events in Australia (e.g., Boening et al., 2012). This event illustrates how climate modes can influence key elements of the global water cycle (precipitation, evapotranspiration and runoff), leading to typical changes in the water storage, summarized with the mass balance equation (Eq. 1):

$$
\frac{d S}{d t}=P-E T-R
$$

where dS/dt are the water storage variations integrated from the surface to the aquifer, $\mathrm{P}$ is the precipitation, ET is the evapotranspiration and $\mathrm{R}$ is runoff. Wind forcing can also become extremely significant over oceans, especially at high latitudes and shallow seas, where large mass transport occurs at interannual time-scales (e.g., Piecuch \& Ponte, 2011; Piecuch et al., 2013). By setting the rhythm of precipitation, evaporation, transpiration, runoff and wind speed, climate modes can exert a profound influence on the variability of water mass distribution across the ocean, atmosphere and continents, which are expected to be observable with GRACE and GRACE-FO satellite gravity missions.

\subsection{Satellite gravity solutions}

Monthly mass variations have been estimated globally using the latest GRACE (Tapley et al., 2004; Tapley et al., 2019) and GRACE-FO (Landerer et al., 2020) mascon solutions produced by the CSR (Center for Space Research) and JPL (Jet Propulsion Laboratory). In this study, mascon solutions have been 
preferred over spherical harmonic solutions, because of a better localization of the origin of mass variations and reduced leakage errors. In turn, mascon solutions use an inversion strategy that cannot be easily reproduced or replicated, relying on specific a priori constraints and regularization procedures. While mascon solutions allow less liberty than spherical harmonics in the choice of background models (e.g., Blazquez et al., 2018) and noise reduction techniques (e.g., Horvath et al., 2018; Kusche et al., 2009), they ensure replicable results from one study to another, as long as the same versions of the same products are used.

In this study, we used the CSR and JPL Level 3 Release 6 mascon solutions, consisting of monthly mass grids spanning from April 2002 to July 2020 at the time of the download (September 2020). All mass changes are assumed to occur within a thin layer at the Earth's ellipsoid surface (WGS84) and are expressed in equivalent water heights. The JPL and the CSR provide global mascon solutions, using $3^{\circ}$ spherical caps (Watkins et al., 2015) and $1^{\circ}$ equal area elements (Save et al., 2016). Because the CSR and JPL solutions are developed, processed and archived in a shared Science Data System (SDS), they harmonize several necessary processing steps. The degree- 1 coefficients are estimated using the methods from Sun et al. (2016), built upon the work of Swenson et al. (2008) suggesting that geocenter motions could be modelled using a combination of GRACE measurements and ocean models. The degree-2, order-zero coefficients ( $C_{20}$ and after August 2016 , the $C_{30}$ coefficients as well) are replaced with the solutions from Satellite Laser Ranging provided by the GSFC (Goddard Space Flight Center) (Loomis et al., 2019). After August 2016, an accelerometer transplant was carried out to compensate for the loss of one of the two accelerometers (Bandikova et al., 2019). The AOD1B RL06 model (Dobslaw et al., 2017a) is used as a background model for the dealiasing of the ocean and atmosphere. In the CSR and JPL solutions, the effect of atmospheric loading on the ocean surface has been restored using the GAD correction (Dobslaw et al., 2017b) and Glacial Isostatic Adjustment (GIA) has been corrected using the ICE6G-D model (Peltier et al., 2018). Besides, the Coastal Resolution Improvement (CRI) filter was applied on JPL mascon solutions, to reduce leakage in coastal areas (Wiese et al, 2016). We did not apply land grid scaling (i.e., gain factors developed for the interpretation of hydrological signals in mascon solutions at higher resolutions; Wiese et al., 2016) to the JPL or CSR mascon solutions, because they are not adapted for fully global analyses including the oceans, continents and ice-covered regions.

The CSR and JPL Level 3 Release 6 mascon solutions were downloaded from the PODAAC website (https://podaac.jpl.nasa.gov), with all corrections listed above applied (Cooley \& Landerer, 2019). In order to convert ocean bottom pressures to ocean mass variations, we removed the GAD from the CSR and JPL mascon solutions and restored the GAB, accounting for the ocean circulation only. To facilitate the comparison of the two solutions, the data have been converted into freshwater anomalies, using a water density of $1000 \mathrm{~kg} \mathrm{~m} \otimes^{3}$ and interpolated on a regular $1^{\circ} \times 1^{\circ}$ grid using a nearest neighbor interpolation. Both CSR and JPL anomalies refer to the 2004-2009.99 time average. Because this study focuses on interannual signals, a secular trend and seasonal signals have been removed at each grid point, using the outputs of an ordinary least squares regression taking simultaneously into account a constant, linear trend, annual sinusoid and semi-annual sinusoid. 


\subsection{Climate indices}

A significant part of the climate variability tends to take place in distinctive patterns repeated in space and time known as climate modes. Climate modes are usually defined as statistically prominent features of the regional climate variability, usually determined by empirical orthogonal functions (EOF) of one or several climate variables in a given region. Here, we consider eight climate indices: the MEI, PDO, NPGO, AMO, NAO, AO, SAM and IOD (Fig. 1).

ENSO is a major actor of the global climate, triggering extreme events such as cyclones, floods, droughts or heat waves in various regions of the world (e.g., Santoso et al., 2017). The MEl is a multi-variable index used to diagnose the mean state of ENSO (Wolter \& Timlin, 1998). It is defined as the leading component of the combined EOF analysis of sea level pressure (SLP), sea surface temperature (SST), zonal and meridional components of the surface wind, and outgoing longwave radiation (OLR) over the tropical Pacific basin $\left(30^{\circ} \mathrm{S}-30^{\circ} \mathrm{N}\right.$ and $\left.100^{\circ} \mathrm{E}-70^{\circ} \mathrm{W}\right)$.

The PDO consists in a decadal SST oscillation, characterized by a basin-wide dipole dividing the North Pacific along a typical northeast - southwest chevron pattern (Mantua et al., 1997). It is defined as the leading EOF of SST anomalies north of $20^{\circ} \mathrm{N}$ in the Pacific region (Newman et al., 2016) and estimated with the ERSSTV5 dataset (Huang et al., 2017). The PDO is closely related to the ENSO and is sometimes referred to as a "Iong-lived ENSO", to characterize the longer periods of the climate index.

The NPGO expresses as a double gyre in the North Pacific (Di Lorenzo et al., 2008). It is defined as the second mode of sea surface height variability in the Northeast Pacific $\left(180^{\circ} \mathrm{W}-110^{\circ} \mathrm{W} ; 25^{\circ} \mathrm{N}-62^{\circ} \mathrm{N}\right)$. Connected with ENSO and PDO, it contributes to global climate variability, which is evidenced by global sea level trends and sea surface temperature (Di Lorenzo et al., 2010).

The AMO consists in a multidecadal SST oscillation across the whole Atlantic basin, with cool and warm phases that may last for 20-40 years (Enfield et al., 2001). We use the unsmoothed index, provided by the NOAA/OAR/ESRL PSL, Boulder, Colorado, USA, from their Web site at https://psl.noaa.gov and calculated from 1948 to present as the area weighted average of the Kaplan SST V2 dataset (Kaplan et al., 1998) over the North Atlantic $\left(0-70^{\circ} \mathrm{N}\right)$.

The NAO index reflects the difference in surface sea level pressure between the Subtropical Azores High and the Subpolar Low (Lamb \& Peppler, 1987). The NAO impacts the intensity and location of the North Atlantic jet streams and storm tracks (Woollings \& Blackburn, 2012). It modulates heat and moisture transport, resulting in temperature and precipitation changes that can extend from North America to central Europe (Hurrell et al., 2003). The monthly NAO index is calculated as the first mode of a Rotated Principal Component Analysis (RPCA) applied on monthly mean 500 millibar height anomaly data from 1950 to 2000 over $0-90^{\circ} \mathrm{N}$ of latitude (Barnston \& Livezey, 1987).

Strongly connected with NAO (Zhou et al., 2001), the AO is a climate pattern characterized by winds circulating counterclockwise around the Arctic at around $55^{\circ} \mathrm{N}$ latitude (Baldwin \& Dunkerton, 1999). 
During positive $\mathrm{AO}$ phases, cold air masses tend to be confined at high latitudes by strong circular winds. During negative $\mathrm{AO}$ phases, cold air masses can more easily move southwards, increasing the storminess at mid-latitudes (Higgins et al., 2000). The AO index is defined as the leading EOF mode of monthly mean 1000 millibar height anomaly data from 1979 to 2000 over $20^{\circ} \mathrm{N}-90^{\circ} \mathrm{N}$.

SAM, also known as the Antarctic oscillation (AAO), is a major driver of climate variability in the Southern Hemisphere (Thompson \& Solomon, 2002). It has been shown to influence windiness, storminess, rainfall and temperatures from the subtropics to Antarctica (Gillett et al., 2006). Defined as a zonal pressure difference between the latitudes of $40^{\circ} \mathrm{S}$ and $65^{\circ} \mathrm{S}$ (Marshall, 2003), it reflects the contraction (in a positive phase) or expansion (in a negative phase) of the westerly winds belt circling Antarctica.

Strongly connected with ENSO, the IOD consists in an interannual oscillation of the SST in the equatorial Indian Ocean, forming a typical west-east dipole (Saji et al., 1999). The Dipole Mode Index (DMI) is defined as the difference of SST averaged in the western $\left(50^{\circ} \mathrm{E}-70^{\circ} \mathrm{E}\right.$ and $\left.10^{\circ} \mathrm{S}-10^{\circ} \mathrm{N}\right)$ and eastern $\left(90^{\circ} \mathrm{E}-\right.$ $110^{\circ} \mathrm{E}$ and $10^{\circ} \mathrm{S}-0^{\circ} \mathrm{N}$ ) equatorial Indian Ocean, and calculated with the HadISST1.1 SST dataset with the 1981-2000 climatology removed.

To be consistent with the processing of satellite gravity solutions, all climate indices have been detrended and DE seasoned. Decadal trends and seasonal signals have been removed using the outputs of an ordinary least squares regression of a linear trend, annual sinusoid, semi-annual sinusoid and a constant carried out for the GRACE/GRACE-FO time period (April 2002 - September 2020). Besides, to facilitate the comparison of climate modes, all indices have been normalized, so that their time average equals zero and their standard deviation equals one.

The MEI, PDO, AMO and DMI (IOD index) are distributed by the NOAA (National Oceanic and Atmospheric Administration) PSL (Physical Science Laboratory) climate data repository

(https://psl.noaa.gov/data/climateindices/). NAO and AO are distributed by the NOAA Climate Prediction Center (https://www.cpc.ncep.noaa.gov/). The NPGO index is available through the NPGO webpage at http://www.o3d.org/npgo/npgo.php. The SAM index is available from Gareth Marshall's webpage: http://www.nerc-bas.ac.uk/icd/gjma/sam.html. All web pages listed above were accessed for the last time on the 14th June 2021.

\subsection{LASSO regression}

Our inversion procedure consists in a suite of time series analyses, carried out independently from one grid cell to another. To assess the relationships between climate modes and water mass changes, we consider the following regression model (Eq. 2):

$$
h(t)=\sum_{i=1}^{8}\left(\beta_{i} \times C_{i}(t)\right)+\beta_{0}+\epsilon
$$


where $\mathrm{h}(\mathrm{t})$ is the change in equivalent water height estimated by GRACE/GRACE-FO at a given location, $\mathrm{C}_{\mathrm{i}}$ is one of the eight climate indices selected in this study (PDO, MEI, NPGO, NAO, AMO, AO, SAM, DMI), the coefficients $\beta_{\mathrm{i}}$ are the parameters to be estimated, $\beta_{0}$ is a constant and $\epsilon$ are the residuals of the regression (i.e., the changes in equivalent water height that are not taken into account by our regression model). A positive $\beta_{i}$ expresses a positive correlation between the observed signal $h(t)$ and climate indices $C_{i}(t)$, while a negative $\beta_{i}$ expresses an anti-correlation. Because it is unlikely for all eight indices to contribute simultaneously to the water mass changes measured at a given location, either on land or over the oceans, the model can be considered as sparse. At a given location, the interannual variability of the water mass changes observed by GRACE and GRACE-FO only depends on a subset of climate indices. This subset is expected to change with the geographical location.

The LASSO is a regularization technique allowing the selection of relevant features in a multiple variable regression model (Tibshirani, 1996). The LASSO minimizes the sum of squared errors, with an upper bound on the sum of the absolute values of the model parameters called the LASSO constraint. The minimization function $\psi$ is then (Eq. 3),

$$
\psi=\sum_{t=1}^{n}\left(h(t)-\sum_{i=1}^{8}\left(\left(\beta_{i} \times C_{i}(t)\right)-\beta_{0}\right)\right)^{2}+\lambda \sum_{i=1}^{8}\left|\beta_{i}\right|
$$

Because of the LASSO constraint, some of the coefficients of the regression model will be set to exactly zero, leading to more interpretable models with less explanatory variables.

The degree of shrinkage of the coefficients $\beta_{i}$ depends on the value of the penalty $\lambda$ (Fig. $2 b$ ). If $\lambda=0$, the regression becomes an ordinary least squares regression. On the other hand, if $\lambda$ is too high, all explanatory variables will be eliminated from the regression model, as all $\beta_{i}$ coefficients will be set to zero (Fig. 2b). The penalty $\lambda$ is therefore calculated to minimize the standard error of a fivefold cross validation (called CV below, see Fig. 2c.) (e.g., Arlot \& Celisse, 2010), i.e., each time series is randomly divided in five parts, successively used as testing (one part) and training (four parts) datasets. This criterion has been shown to work well in the presence of correlated variables (Hebiri \& Lederer, 2013). This procedure is similar to the approach of Pfeffer et al. (2018), who extracted climate mode fingerprints for the PDO, ENSO, NPGO, AMO, IOD and IOBM (Indian Ocean Basin Mode; Yang et al., 2007) in historical reconstructions of steric sea levels.

This procedure allows selecting the most relevant climate indices to reproduce interannual water mass changes at each geographical location sampled by the GRACE/GRACE-FO mascon solutions. However, because of the LASSO constraint, the amplitude of coefficients diminishes (Tibshirani, 1996). To recover the optimal values of the regression model coefficients $\left(\beta_{i}\right)$, an ordinary least squares (OLS) regression is carried out at each geographical location, using a simpler regression model, including only the climate 
indices selected with the LASSO. This final step avoids the shrinkage of the regression model coefficients $\left(\beta_{\mathrm{i}}\right)$, but keeps the selection capacity of the LASSO (Table 1).

We tested our inversion procedure with a synthetic test. Synthetic data were generated using the regression model (Eq. 1) with $\beta_{\mathrm{i}}$ coefficients equal to $10,7.5$ and 5 for MEI, NAO and DMI and 0 for PDO, NPGO, AMO, AO, SAM. We added noise to the synthetic data, using a random sample from a normal distribution centered on zero with a standard deviation of 10 . This level of noise is quite strong, as it is the same amplitude of the synthetic ENSO signal, and is significantly larger than the NAO $\left(\beta_{\mathrm{NAO}}=7.5\right)$ and IOD $\left(\beta_{I O D}=5\right)$ signals. We chose these coefficients to (i) test whether the LASSO is able to set the PDO, NPGO, AMO, AO and SAM coefficients to exactly zero and (ii) disentangle correlated predictors in the presence of noise (for example MEI and PDO or NAO and AO, see online resource Fig. OR9). The results are shown in Fig. 2 and Table 1. As expected, a classic OLS inversion is not able to select the relevant predictors of the water mass variability, as all coefficients are non-null (Table 1). However, the amplitudes of MEI, NAO and IOD coefficients are close to synthetic values (Table 1). With a LASSO regression, the value of the $\beta_{i}$ coefficients diminishes with the penalty $\lambda$ (Fig. 2b). Optimal values of the penalty can be estimated with a CV procedure (Fig. 2C). The penalty minimizing the average CV error is not sufficient to set the PDO value to zero (Table 1, Fig. 2b), which is likely due to the fact that the PDO is correlated with MEI (online resource Fig. OR9). On the other hand, the penalty minimizing the standard error, which takes into account the dispersion due to the random division of the dataset during the $\mathrm{CV}$ procedure, is able to select the relevant predictors of the regression model (MEI, NAO and IOD) and set all other parameters to exactly zero. The final OLS regression carried out on the selected predictors succeeds in recovering the full amplitude of ENSO, NAO and IOD signals (Table 1).

\section{Results}

\subsection{Climate mode fingerprints}

Climate mode fingerprints are defined as the spatial distribution of $\beta_{i}$ coefficients (Eqs. 2 and 3 ) resulting from the inversion of climate indices with a suite of LASSO and a final least squares regressions. The climate mode fingerprints of the JPL (Fig. 3) and CSR (Fig. 4) are extremely similar, though the CSR climate mode fingerprints seem to be sparser (more null values), especially across arid areas (Sahara, central Asia, central Australia). For comparison, a classical EOF analysis of the water mass changes observed by GRACE and GRACE-FO and the inferred correlations with climate indices are presented in the online resource (OR).

ENSO has a strong impact on the interannual variability of both continental and oceanic water mass changes. Negative ENSO anomalies (Fig. $\mathbf{3 b}$ and $\mathbf{4 b}$ ) indicate a water shortage during El Niño phases and a water excess during La Niña. For example, negative anomalies in Australia correspond to wet Niña and dry Niño conditions (in red in Fig. $3 b$ and $\mathbf{4 b}$ ), having the potential to drive extreme rainfall and floods during La Niña (e.g., Evans and Boyer-Soucher 2012; Boening et al. 2012) and disastrous droughts and 
wildfires during El Niño (e.g., Mariani et al. 2016; Wang and Cai. 2020). The largest negative ENSO anomalies are located in West Antarctica (down to $-120 \mathrm{~mm}$ ), in the North of the Amazon basin (down to $-80 \mathrm{~mm}$ ) and in the Gulf of Carpentaria (down to $-60 \mathrm{~mm}$ ). A large (10 to $15 \mathrm{~mm}$ ) positive anomaly lies across the Southern Pacific and the Southern Ocean, likely indicating the transport of hot water from the tropical Pacific to the Southern Ocean during El Niño events, which would accelerate ice-melting in West Antarctica. This South Pacific - Southern Ocean anomaly was also detected in the EOF analyses of the CSR and JPL solutions (online resource; Figs. OR1, OR2 \& OR3) and is consistent with previous studies (e.g., Paolo et al., 2018; see Sect. 4.2 for further details). In general, ENSO seems to have a large impact on the interannual variability of water mass distributions in shallow seas (Gulf of Carpentaria and around Indonesia) and continental water storage globally (e.g., North of the Amazon basin, Central America, Okavango and Zambesi basins, Northeast of Australia, Penner basin, Eastern Europe, West Siberia, West coast of Canada, Winnipeg Lake, East coast of USA).

The PDO fingerprint (Fig. 3a and 4a) is correlated with the MEl fingerprint (Fig. $\mathbf{3 b}$ and $\mathbf{4 b}$ ), with some noticeable differences, confirming the tight but complex relationships between the two modes. The PDO mostly impacts land water storage, despite potential influences over the South Pacific and Southern Ocean of large geographical extent but extremely small amplitude (less than $5 \mathrm{~mm}$ ). The PDO resembles MEl in the North East of the Amazon, over Northwest America, in Africa, North East Australia, large parts of Eastern Europe and the North of Asia. The PDO differs from MEI in the Parana basin, across South East Asia and over the oceans in general. This tends to show that the PDO and MEl have complementary mass transport fingerprints, both representative of ENSO, with correlated but distinct periodicities (see the PDO and MEl times series in Fig. 1 and their spectral content in the online resource: Fig. OR8).

The NPGO fingerprint (Fig. $\mathbf{3 c}$ and $\mathbf{4 c}$ ) adds another element to the complex ensemble of Pacific teleconnections. This regional mode, recently detected in the variability of sea surface heights in the Pacific (Di Lorenzo et al., 2008), has, rather unexpectedly, a lot of common variability with land hydrology over the GRACE/GRACE-FO time period. Some of it might be due to fortuitous correlations of water mass changes with the climate index, especially over arid regions such as the Sahara, the Arabian Peninsula or central Asia, where we do not expect much hydrological signal (Fig. 3c). Remarkably, the CSR and JPL fingerprints differ for the NPGO over the above-mentioned regions. The CSR displays a sparser NPGO fingerprint, with values that are generally null for arid areas (Fig. 4c). The large majority of spatial patterns is however consistent between the two centers. The NPGO fingerprint also seems to be anticorrelated with MEl, over the Zambezi basin, in Northeast Australia, in Northeast America and in central Europe (Fig. 4c). We do expect a physical impact of the NPGO around the North Pacific basin and such signatures are indeed present in Alaska, along the West coast of Canada and in California (Fig. 3c and 4c).

AMO (Fig. 3d and 4d) influences the interannual variability of land water storage along the Amazon River, North of California, the extreme South of Alaska and the North of British Columbia, the Middle East and eastern Mediterranean, in between the Ob and Yenisei rivers in Siberia, across Myanmar and Thailand and in the Zambezi River basin. The impact of AMO on interannual ocean mass changes seems to be 
negligible. It might be noted that the impact of $\mathrm{AMO}$ on the interannual hydrological variability remains strong in the Amazon River basin, even for extremely high penalties (not shown here), which makes it extremely robust.

Unlike the PDO, NGPO and AMO fingerprints, AO (Fig. 3e and 4e), NAO (Fig. $\mathbf{3 f}$ and $\mathbf{4 f}$ ) and SAM (Fig. $\mathbf{3 g}$ and $\mathbf{4 g}$ ) have clear and robust influences on the ocean mass transport, but do not impact the interannual variability of the continental water storage. As expected, the $\mathrm{AO}$ influences interannual water mass transport over the Arctic, the North Atlantic and the North Pacific (Fig. 3e, 4e). The AO also influences water mass transport in the Mediterranean Sea (Fig. 3e, 4e). NAO is significantly correlated with AO (R > 0.6 in online resource Fig. OR9). As a consequence, $A O$ seems to have been favored over NAO, and the NAO fingerprint is almost null everywhere, except over the Arctic and North Atlantic (Fig. 3f, 4f), which intensifies the impact of $\mathrm{AO}$ (Fig. 3e, 4e). The SAM fingerprint exhibits a clear bipolar anomaly across the Southern Ocean, positive near the coast of Antarctica, and negative away from the Antarctic coastline (Fig. $\mathbf{3 g}$ and $\mathbf{4 g}$ ).

The IOD (Fig. 3h and $\mathbf{4 h}$ ) seems to have a rather limited impact on the interannual variability of the water mass transport both on land and in the ocean. Positive and negative anomalies are found in the JPL and CSR solutions in southeastern Europe, in California, in the Pacific and Indian Ocean and in the Java Sea.

\subsection{Selection capacity of the LASSO}

We introduced a LASSO regularization to improve the interpretability of our model through the selection of relevant predictors of the climate variability at interannual time scales. The climate mode fingerprints resulting from the LASSO inversion are sparse; for each pair of geographical coordinates most of the $\beta_{\mathrm{i}}$ coefficients (Eqs. 2 and 3 ) are set to zero. One way to look at this is through the L0-norm, indicating the number of non-zero $\beta_{\mathrm{i}}$ coefficients in the regression model. The L0-norm can range from zero (all climate indices are eliminated from the regression model) to eight (all climate indices are selected in the regression model).

For the JPL and CSR solutions (Fig. 5), the LASSO regularization, coupled with a 5 -fold cross validation minimizing the standard error, performed efficient variable selection on a global scale. The L0-norm is set to zero for large parts of the Atlantic Ocean, Indian Ocean and Pacific Ocean. Interannual ocean mass changes are indeed expected to be negligible, except for high-latitude regions and shallow seas (Piecuch \& Ponte, 2011; Piecuch et al., 2013). SAM, MEI and AO contribute significantly to the interannual variability of ocean mass in the Arctic, Southern Ocean, Mediterranean Sea, Northern Pacific and shallow seas in the North of Australia and around Indonesia (Fig. 3, 4), leading to non-zero L0-norms in these regions (Fig. 5). We would also expect the L0-norm to be close to zero in arid areas, where not much climate variability is observed. For the CSR, the LO-norm is indeed equal to zero over the Sahara, Arabian Peninsula, central Asia and South West Australia. For the JPL, the outputs of the LASSO regression seem noisier, with non-null coefficients over the same arid areas. 
Besides, the L0-norm should not be too high in any region of the world. It seems unlikely for all climate modes to contribute to the interannual water mass transport observed in one place. Some of the climate modes are correlated (such as PDO, MEI and IOD or AO and NAO) and there are some known teleconnections between them. It would therefore seem realistic for 3 or 4 climate modes to contribute together to the interannual variability observed in one place, but more than that seems unlikely. Looking at high values of the L0-norm can therefore give us an indication of the presence of noise in the climate mode fingerprints. Our method is rather successful in this regard on a global scale (Fig. 5), though there is some noise remaining in the outputs of the regression that can be identified in rare locations by high LOnorm values (values above 5 or 6 ).

High L0-norm values are not found in the same places for the CSR and JPL solutions. For the CSR, high L0-norm values are found near the coast, especially between Greenland and Canada, suggesting noisier solutions in these regions, potentially due to unresolved leakage issues. This issue is not reproduced in the JPL solutions, maybe due to the application of the Coastline Resolution Improvement (CRI) filter (Wiese et al., 2016). However, we found high L0-norm values for the JPL solutions in semi-arid to arid areas such as central Asia, West Africa and Southern California (Fig. 5). This may be due to different regularization strategies used to lessen the noise in the mascon solutions, based on geophysical models for the JPL (Watkins et al., 2015) and on an iterative procedure weighting the signal to noise level for the CSR (Save et al., 2016). If the hydrological model (GLDAS NOAH; Rodell et al., 2004) used to constrain terrestrial water storage is unsatisfactory across semi-arid and arid areas, it might let noise in the JPL mascon solutions that could be retrieved in the results of our inversion.

\subsection{Performance of climate modes predictions}

The model performance can also be assessed using determination coefficients $\left(R^{2}\right)$, interpreted as the fraction of variance explained by the regression model compared to the variance measured in locally detrended and deseasoned gravity solutions (Fig. 6). The RMS (root mean square) of locally detrended and deseasoned CSR and JPL solutions (Fig. $\mathbf{6 a}$ and $\mathbf{b}$ ) ranges from a few millimeters in the tropical Atlantic, to a few centimeters on land, to more than half a meter across fast thinning glaciers located in Greenland and Antarctica.

According to our regression model, the eight climate modes considered in this study contribute less than a centimeter to the interannual variations observed in tropical ocean basins with amplitudes of less than $2 \mathrm{~cm}$. $R^{2}$ values reach at most $30 \%$ in the tropical Pacific (Fig. $6 \mathrm{e}$ and $\mathrm{f}$ ), due to the combined effect of the PDO, MEI and SAM (Figs. 3 and 4). In extra-tropical ocean basins, climate modes (RMS up to $25 \mathrm{~mm}$ ) contribute for about 20 to $50 \%$ to the interannual variability observed in the CSR and JPL solutions (Fig. 6). It is due to the combined effect of SAM and ENSO in the Southern Ocean and NAO and AO in the Arctic (Figs. 3 and 4). In shallow seas, climate modes contribute for several centimeters (RMS up to $7 \mathrm{~cm}$ in the Gulf of Carpentaria) to the observed interannual variability (RMS up to $10 \mathrm{~cm}$ in the Gulf of Carpentaria), which explains from 20 to $70 \%$ of the observed signal (Fig. 6). In the Gulf of Carpentaria, 
most of the climate variability is explained with ENSO, and for the Mediterranean Sea a significant part (from 30 to $40 \%$ ) of the interannual variability is explained with AO (Figs. 3 and 4).

The largest contributions of climate modes to interannual terrestrial water storage changes (excluding glaciated regions) are found in the Zambezi, North Amazon and Parana basins (Fig. 6), where the combined effect of the PDO, ENSO, NPGO and AMO (Figs. 3 and 4) generates interannual signals with an RMS reaching 130, 110 and $90 \mathrm{~mm}$ respectively. The effect of combined climate modes explains up to $60 \%$ of the interannual terrestrial water storage variability in the Zambezi and North Amazon basins and $40 \%$ in the Parana basin. Significant interannual variations (with RMS ranging from 30 to $80 \mathrm{~mm}$ ) in the terrestrial water storage are also generated by climate modes in North Australia, Indonesia, South East Asia, India, along the Tigris and Euphrates rivers, across the Caspian Sea, in the Ob and Yenisei basins, in Eastern Europe, in central America, along the Gulf of Mexico (in Florida in particular), in California, over the Great Lakes and in Canada. The PDO, ENSO, NPGO and AMO are responsible for most of the interannual terrestrial water storage changes (with $\mathrm{R}^{2}$ values ranging from 20 to $70 \%$ depending on the region considered), though $\mathrm{AO}$ and NAO were found to contribute around the Mediterranean Sea, and the IOD was found to have a rather surprising influence in Central Europe. However, for several large regions of the world, such as central South America, central North America, West Africa, tropical Africa (including the Congo basin), North India, South East China and North West Australia, significant interannual variability of the terrestrial water storage is observed with GRACE and GRACE-FO measurements, that failed to be reproduced with our simple regression model. This is likely due to the occurrence of other processes that may be climate related, but are not adequately represented by climate modes. Geophysical processes (e.g., earthquakes) or anthropogenic influences (e.g., land use change, groundwater pumping) are also known to influence the variability of the mass transport measured by GRACE and GRACE-FO, and are not taken into account by climate modes.

Ice mass changes over glaciated regions (e.g., West Antarctica, Greenland, Alaska, Svalbard and the Andes) also display significant interannual variability, with RMS values ranging between 100 and 500 $\mathrm{mm}$ after removal of a linear trend, an annual sinusoid and a semi-annual sinusoid (Fig. 6a and b). Climate modes contribute actively to the interannual ice mass variability, by enhancing/reducing precipitation and/or bringing cold/hot air and ocean masses near the glaciers, leading to RMS values ranging between 200 and $500 \mathrm{~mm}$ in Svalbard, 100 and $250 \mathrm{~mm}$ in Greenland, 50 to $200 \mathrm{~mm}$ in West Antarctica and in Alaska. Surprisingly AO and SAM seem to have a negligible effect on the interannual variability of ice mass changes (Figs. 3 and 4), while the PDO, ENSO, NPGO and AMO explain between 30 and $50 \%$ of the interannual variability in Greenland and West Antarctica (Fig. 6 e and f) and up to $70 \%$ in Alaska (Fig. 6e and f).

\section{Discussion}

\subsection{Implications for climate applications}


Climate modes contribute significantly to the interannual variability in the global water cycle. The GRACE and GRACE-FO measurements offer the unique opportunity to monitor the water mass displacements through the atmosphere, the ocean and the continents. During positive phases of ENSO (El Niño events), we can detect a water mass uptake (negative anomaly in red) in intertropical regions (i.e., Gulf of Carpentaria, shallow seas around Indonesia, North East Australia, North Amazon and Zambezi basin) transported to high latitudes, and resulting in a positive anomaly (in blue) across the Southern Pacific and Southern Ocean. This transport of warm waters is in turn responsible for significant ice melting (red anomaly) in West Antarctica (in particular along the Pine Island and Thwaites glaciers) and at the Southwest of the Antarctic Peninsula (Fig. $\mathbf{3 b}$ and $\mathbf{4 b}$ ). The opposite happens during negative phases of ENSO (La Niña events), resulting in significant interannual variability (Fig. $\mathbf{6 c}$ and d). This is in agreement with the study by Paolo et al., 2018, showing that the net ice shelf mass decreases during intense El Niño events in the Antarctic Pacific sector due to basal melting.

The impact of ENSO, depicted with the MEI index and fingerprint, has to be combined with other climate modes such as the PDO, NGPO, AMO and SAM. Indeed, in the Southern Ocean, the combined effect of ENSO (Fig. $\mathbf{3 b}$ and $\mathbf{4 b}$ ) and SAM (Fig. $\mathbf{3 g}$ and $\mathbf{4 g}$ ) contributes to move water masses and accelerates/decelerates ice melting in West Antarctica (e.g., Paolo et al., 2018). More generally, interannual water mass transport both on land and in the ocean depends on complex wind regimes, precipitation and temperature conditions related with several climate modes (e.g., Petrick et al., 2014; $\mathrm{Ni}$ et al., 2018; Ndehedehe \& Ferreira, 2020; Liu et al., 2020). This is evidenced, for example in South America, where a combination of AMO, PDO and ENSO is necessary to explain the interannual variability of the water storage along the Amazon River, in the North of the Amazon basin, along the Atlantic Brazilian coast and within the Parana basin (Fig. 3a, b, $\mathbf{d}$ and $\mathbf{4}$ a,b,d). AMO has indeed been shown to interact with ENSO in the Amazon basin, through the exchange of moisture in key tropical regions (e.g., García-García \& Ummenhofer, 2015).

Besides, it has been widely shown that ENSO is better depicted with a large variety of climate indices, including but not limited to $\mathrm{MEI}$ and the PDO, to catch the variety of timescales (from biennial to decadal) and spatial patterns associated with this global climate mode, influencing both the sea level (e.g., Zhang \& Church, 2012) and terrestrial water storage (Fasullo et al., 2016; Luo et al., 2016). This is clearly shown in the correlation of $\mathrm{MEl}$ and PDO fingerprints that are both needed to describe ENSO. More unexpectedly, the NPGO seems to complement the MEI and PDO fingerprints, and contributes significantly to interannual water mass displacements around the globe (Fig. 3a,b,c and $\mathbf{4}$ a,b,c). The three Pacific teleconnections should therefore be interpreted together. Several studies confirm the emerging influence of the NPGO in recent decades (Di Lorenzo et al., 2008; Ye et al., 2016, and its association with the PDO and ENSO (Di Lorenzo et al., 2010; Zhang et al., 2013). The changing nature of the PDO, ENSO and NPGO could also be associated with global warming. The non-stationary nature of climate modes is evidenced, among others, by increased association of the NPGO with the first mode of climate variability in the North Pacific usually associated with the PDO (Litzow et al., 2020). The GRACE and GRACE-FO record being extremely limited in time (here July 2002 - August 2020) would therefore only offer a temporary snapshot of the interactions between the water mass displacements and climate modes. 
Remarkably, while the PDO, MEI, NGPO and AMO influence the interannual variability of terrestrial water storage; NAO, AO and SAM mostly impact interannual ocean mass changes in extratropical ocean basins (i.e., the Arctic and Southern Ocean) and shallow seas (i.e., the Mediterranean Sea, Gulf of Carpentaria and the ensemble of shallow seas bordering Indonesia). SAM has a clear impact on the Southern Ocean circulation (Fig. $\mathbf{3 g}$ and $\mathbf{4 g}$, largely due to the wind regime, which is in line with the findings of Bergmann \& Dobslaw (2012), Makowski et al. (2015) and Liau \& Chao (2017). As NAO and AO are highly correlated, AO was favored over NAO and explained a large part of the ocean mass variability in the Arctic, North Atlantic and Mediterranean Sea. This is in good agreement with the findings of Peralta-Ferriz et al. (2014), Peralta-Ferriz et al. (2016) and Landerer \& Volkov (2013). It also evidences the capacity of the LASSO to choose among several correlated predictors and select the most relevant to predict the observations considered.

Climate modes are therefore important to predict the interannual hydrological and ocean mass variability. However, for large regions of the world, our model is unable to explain the GRACE/GRACE-FO observations. Other mechanisms should be invoked that are not likely to be well represented with a simple empirical model, but rather require to solve the water mass balance with global hydrological models. In future studies, it could also be useful to investigate the possibility of a lagged response of the water mass displacements to climate modes, which has been shown to be significant for various regions of the world (Phillips et al., 2012; Kundzewicz et al., 2019).

\subsection{Implications for geodetic applications}

GRACE and GRACE-FO measurements offer a unique view of the global mass transport within the whole Earth system at interannual scales. The model suggested in this study, based on a suite of robust LASSO inversions of multiple climate indices, provides an efficient way to automatically correct the satellite gravity solutions for relevant modes of the climate variability. Though climate modes often explain a marginal part (less than $50 \%$ ) of the interannual equivalent water mass transport, the predicted signals reach amplitudes that can be easily aliased with other sources of mass transport and mask weaker processes of geodetic interest. Over extratropical ocean basins and shallow seas, the ocean mass transport due to climate modes can reach several centimeters at interannual scales. In large hydrological basins, such as the Amazon, the Zambezi or the Parana, the interannual variability of the terrestrial water storage predicted by climate modes reaches about $10 \mathrm{~cm}$. Over glaciated regions, climate modes generate interannual variations in the ice mass reaching up to $50 \mathrm{~cm}$.

Such signals are significantly larger than the uncertainty on GRACE and GRACE-FO solutions (e.g., Riegger et al., 2012; Scanlon et al., 2016; Ferreira et al., 2016; Blazquez et al., 2018) and need to be corrected in order to unveil small amplitude signals originating, for example, from anthropogenic climate change (e.g., Fasullo et al., 2016) or deep Earth interior processes (e.g., Mandea et al., 2012 and 2015). The increase of global mean ocean mass due to freshwater inputs reaches only $2.3+/-0.19 \mathrm{~mm} / \mathrm{yr}$ over the Jan. 2005 - Dec. 2016 time-period (Cazenave et al., 2018), with interannual variations of about $+/-5$ $\mathrm{mm}$ that can be easily aliased with climate modes (Hamlington et al., 2019). Trends in total terrestrial water storage range from 0 to $+/-20 \mathrm{~mm} / \mathrm{yr}$ (Rodell et al., 2018), with interannual variations of about +/- 
$50 \mathrm{~mm}$ (Tapley et al., 2019). Changes in the ocean circulation can lead to interannual variations in the water mass transport of about +/- $20 \mathrm{~mm}$ (Landerer et al., 2015). Because GRACE and GRACE-FO measurements provide an integrated measurement of the temporal changes in the gravity field, independent models are needed to dealiase the sources of mass variability. The model designed in this study could therefore be used as a global correction for eight different climate modes leading to significant mass changes in various regions of the world. Special attention has been paid to the robustness of the correction, taking only into account significant predictors of the water mass variability. However, the correction would have a limited scope as the numerous processes contributing to the interannual variability of the climate system cannot all be represented with climate modes.

Besides, climate mode fingerprints provide a framework to compare interannual signals from different solutions, allowing to link subtle choices in the processing strategy (e.g., the regularization, filters applied to reduce leakage) to relatively simple parametric results (i.e., a limited number of maps representative of different climate modes).

\section{Conclusions}

The measurements of the GRACE and GRACE-FO satellite gravity missions have now reached enough maturity and precision to allow the detection of typical oscillations of the water mass distributions related to climate modes through (i) the enhancement/reduction of precipitation, evapotranspiration and runoff, (ii) transport of moisture across the atmosphere and (iii) wind forced ocean circulation. Climate modes contribute significantly to the interannual variations in ocean mass (up to $25 \mathrm{~mm}$ in extratropicalbasins and up to $70 \mathrm{~mm}$ in shallow seas), terrestrial water storage (up to $100 \mathrm{~mm}$ in large hydrologic basins such as the Amazon, Zambezi or Parana) and ice thickness (up to $500 \mathrm{~mm}$ in equivalent water heights). While climate modes have already been detected in satellite gravity observations by several independent research teams, this study is the first to account for the teleconnections of eight major climate modes in the global water cycle.

Over the oceans, much of the interannual variability is observed in extratropical basins and shallow seas. The principal actors (among the climate modes selected) of the interannual ocean variability are ENSO (nearly all extratropical basins and shallow seas), SAM (Southern Ocean) and AO (Arctic, North Atlantic, Mediterranean Sea).

Over the continents, a large part of the interannual variability of the terrestrial water storage can be attributed to four climate modes, namely AMO, ENSO, PDO and NGPO. When combined together, these four modes explain up to $60 \%$ of the interannual storage variability observed in the North Amazon, the Zambezi Basin and up to $40 \%$ in the Parana basins, where climate modes predictions generate RMS values up to $10 \mathrm{~cm}$.

In other parts of the world (grey areas in Fig. 6 e and f), our climate modes predictions are unable to fully explain the interannual variability of terrestrial water storage observed by GRACE and GRACE-FO measurements. This may be due to the fact that we did not consider a lagged response of the terrestrial water storage to climate modes (e.g., Phillips et al., 2012) or more likely due to the influence of other 
climatic, anthropogenic and hydrologic processes that require more sophisticated models able to solve the water mass balance depending both on climate conditions and land use changes.

One important result of this study lies in our ability to track interannual water mass displacements across different reservoirs. For example, we can link the transport of water from intertropical regions (both on land and in the tropical Pacific) to the Southern Ocean, where it contributes to the interannual variability of ice mass changes in West Antarctica in connection with ENSO, SAM and PDO. Another significant finding stresses the need to combine several climate indices in order to be able to predict interannual changes in water mass displacements. The variations in terrestrial water storage depend indeed on several factors (wind, temperature, precipitation) influencing the climate regime that are better represented by a combination of climate modes than by a single one. We also found that the NPGO is an important driver of interannual water mass transport globally, which may be due to a recent association of the NPGO with the PDO and ENSO (Di Lorenzo et al., 2010). Such patterns might be transitory, and it is expected that some of the relationships evidenced here will not last because of global warming and global climate change (Litzow et al., 2020).

Our findings show the necessity to maintain our climate observation system, including satellite gravity measurements, in order to extend the length and scope of instrumental records used to diagnose the state of our water resources and predict its future evolution. Finally, the present study will be of great help for better separating, in the GRACE/GRACE-FO data, the climate-related signals occurring in the surface fluid Earth's envelopes from deep Earth signals due to fluid motions in the outer core and to exchange of matter at the core-mantle boundary (Mandea et al., 2012 and 2015).

\section{Declarations}

Funding: This project has received funding from the European Research Council (ERC) under the European Union's Horizon 2020 research and innovation program (GRACEFUL Synergy Grant agreement No 855677).

Conflicts of interest/Competing interests: The authors declare no conflict of interest

Availability of data and material: All data presented in this manuscript will be made freely available online upon acceptance of publication

Code availability: The authors used python toolboxes (numpy, scipy, astropy, statmodels, matplotlib) freely available online. The statistical tools (such as LASSO regressions) used in this paper are already available online.

\section{Acknowledgments}

This project has received funding from the European Research Council (ERC) under the European Union's Horizon 2020 research and innovation program (GRACEFUL Synergy Grant agreement No 855677). 


\section{References}

1. AghaKouchak A, Cheng L, Mazdiyasni O, Farahmand A (2014) Global warming and changes in risk of concurrent climate extremes: Insights from the 2014 California drought. Geophys Res Lett 41(24):8847-8852

2. Anyah RO, Forootan E, Awange JL, Khaki M (2018) Understanding linkages between global climate indices and terrestrial water storage changes over Africa using GRACE products. Science of The Total Environment 635:1405-1416. https://doi.org/10.1016/j.scitotenv.2018.04.159

3. Arlot S, Celisse A (2010) A survey of cross-validation procedures for model selection. Statist Surv 4:40-79. https://doi.org/10.1214/09-SS054

4. Baldwin MP, Dunkerton TJ (1999) Propagation of the Arctic Oscillation from the stratosphere to the troposphere. Journal of Geophysical Research: Atmospheres 104(D24):30937-30946

5. Bandikova T, McCullough C, Kruizinga GL, Save H, Christophe B (2019) GRACE accelerometer data transplant. Adv Space Res 64(3):623-644

6. Barichivich J, Gloor E, Peylin P, Brienen RJ, Schöngart J, Espinoza JC, Pattnayak KC (2018) Recent intensification of Amazon flooding extremes driven by strengthened Walker circulation. Science Advances 4(9):eaat8785

7. Barnston AG, Livezey RE (1987) Classification, seasonality and persistence of low-frequency atmospheric circulation patterns. Mon Weather Rev 115(6):1083-1126

8. Becker M, Meyssignac B, Xavier L, Cazenave A, Alkama R, Decharme B (2011) Past terrestrial water storage (1980-2008) in the Amazon Basin reconstructed from GRACE and in situ river gauging data. Hydrol Earth Syst Sci 15(2):533-546. https://doi.org/10.5194/hess-15-533-2011

9. Bergmann I, Dobslaw H (2012) Short-term transport variability of the Antarctic Circumpolar Current from satellite gravity observations. Journal of Geophysical Research: Oceans, 117(C5). https://doi.org/10.1029/2012JC007872

10. Blazquez A, Meyssignac B, Lemoine J, Berthier E, Ribes A, Cazenave A (2018) Exploring the uncertainty in GRACE estimates of the mass redistributions at the Earth surface: implications for the global water and sea level budgets. Geophys J Int 215(1):415-430.

https://doi.org/10.1093/gji/ggy293

11. Boening C, Willis JK, Landerer FW, Nerem RS, Fasullo J (2012) The 2011 La Niña: So strong, the oceans fell. Geophys Res Lett, 39(19). https://doi.org/10.1029/2012GL053055

12. Capotondi A, Wittenberg AT, Newman M, Di Lorenzo E, Yu J-Y, Braconnot P et al (2015) Understanding ENSO diversity. Bull Am Meteor Soc 96(6):921-938

13. Cazenave A, Meyssignac B, Ablain M, Balmaseda M, Bamber J, Barletta V, ... Wouters B (2018) Global sea-level budget 1993-present. Earth System Science Data 10(3):1551-1590

14. Chen JL, Wilson CR, Tapley BD (2010) The 2009 exceptional Amazon flood and interannual terrestrial water storage change observed by GRACE. Water Resources Research, 46(12) 
15. Cooley SS, Landerer FW (2019) Gravity Recovery and Climate Experiment Follow-on (GRACE-FO) Level-3 data product user handbook. Jet Propulsion Laboratory California Institute of Technology

16. Di Lorenzo E, Schneider N, Cobb KM, Franks PJS, Chhak K, Miller AJ et al (2008) North Pacific Gyre Oscillation links ocean climate and ecosystem change. Geophysical Research Letters, 35(8)

17. Di Lorenzo E, Cobb KM, Furtado JC, Schneider N, Anderson BT, Bracco A et al (2010) Central pacific El Nino and decadal climate change in the North Pacific ocean. Nat Geosci 3(11):762-765

18. Dobslaw H, Bergmann-Wolf I, Dill R, Poropat L, Thomas M, Dahle C et al (2017a) A new highresolution model of non-tidal atmosphere and ocean mass variability for de-aliasing of satellite gravity observations: AOD1B RL06. Geophys J Int 211(1):263-269

19. Dobslaw H, Bergmann-Wolf I, Dill R, Poropat L, Flechtner F (2017b) Product Description Documentfor AOD1B Release 06. GFZ German Research Centre for Geosciences Department 1: Geodesy. Retrieved from https://podaac-tools.jpl.nasa.gov/drive/files/allData/grace/docs/AOD1B_PDD_RL06_v6.1.pdf

20. Easterling DR, Kunkel KE, Wehner MF, Sun L (2016) Detection and attribution of climate extremes in the observed record. Weather Climate Extremes 11:17-27

21. Eicker A, Forootan E, Springer A, Longuevergne L, Kusche J (2016) Does GRACE see the terrestrial water cycle "intensifying"? Journal of Geophysical Research: Atmospheres 121(2):733-745

22. Enfield DB, Mestas-Nuñez AM, Trimble PJ (2001) The Atlantic multidecadal oscillation and its relation to rainfall and river flows in the continental US. Geophys Res Lett 28(10):2077-2080

23. Evans JP, Boyer-Souchet I (2012) Local sea surface temperatures add to extreme precipitation in northeast Australia during La Niña. Geophysical Research Letters, 39(10)

24. Fasullo JT, Lawrence DM, Swenson SC (2016) Are GRACE-era Terrestrial Water Trends Driven by Anthropogenic Climate Change? Advances in Meteorology, 2016, 4830603. https://doi.org/10.1155/2016/4830603

25. Ferreira VG (2016) Uncertainties of the Gravity Recovery and Climate Experiment time-variable gravity-field solutions based on three-cornered hat method. J Appl Remote Sens 10(1):1-20. https://doi.org/10.1117/1.JRS.10.015015, Montecino, D., Yakubu, C. I., \& Heck, B

26. García-García D, Ummenhofer CC (2015) Multidecadal variability of the continental precipitation annual amplitude driven by AMO and ENSO. Geophys Res Lett 42(2):526-535. https://doi.org/10.1002/2014GL062451

27. Gillett NP, Kell TD, Jones PD (2006) Regional climate impacts of the Southern Annular Mode. Geophysical Research Letters, 33(23)

28. Hamlington BD, Cheon SH, Piecuch CG, Karnauskas KB, Thompson PR, Kim K-Y et al (2019) The Dominant Global Modes of Recent Internal Sea Level Variability. Journal of Geophysical Research: Oceans 124(4):2750-2768. https://doi.org/10.1029/2018JC014635

29. Hebiri M, Lederer J (2013) How Correlations Influence Lasso Prediction. IEEE Trans Inf Theory 59(3):1846-1854. https://doi.org/10.1109/TIT.2012.2227680 
30. Higgins RW, Leetmaa A, Xue Y, Barnston A (2000) Dominant factors influencing the seasonal predictability of US precipitation and surface air temperature. J Clim 13(22):3994-4017

31. Horvath A, Murböck M, Pail R, Horwath M (2018) Decorrelation of GRACE time variable gravity field solutions using full covariance information. Geosciences 8(9):323

32. Hu Q, Feng S, Oglesby RJ (2011) Variations in North American summer precipitation driven by the Atlantic multidecadal oscillation. J Clim 24(21):5555-5570

33. Huang B, Thorne PW, Banzon VF, Boyer T, Chepurin G, Lawrimore JH et al (2017) Extended reconstructed sea surface temperature, version 5 (ERSSTv5): upgrades, validations, and intercomparisons. J Clim 30(20):8179-8205

34. Hurrell JW, Kushnir Y, Ottersen G, Visbeck M (2003) An overview of the North Atlantic oscillation. Geophysical Monograph-American Geophysical Union 134:1-36

35. Kaplan A, Cane M, Kushnir Y, Clement A, Blumenthal M, Rajagopalan B, Analyses of global sea surface temperature 1856-1991, Journal of Geophysical Research, 103, 18,567 - 18,589, 1998

36. Kayano MT, Capistrano VB (2014) How the Atlantic multidecadal oscillation (AMO) modifies the ENSO influence on the South American rainfall. Int J Climatol 34(1):162-178

37. Kayano MT, Capistrano VB, Andreoli RV, de Souza RA (2016) A further analysis of the tropical Atlantic SST modes and their relations to north-eastern Brazil rainfall during different phases of Atlantic Multidecadal Oscillation. Int J Climatol 36(12):4006-4018

38. Knight JR, Folland CK, Scaife AA (2006) Climate impacts of the Atlantic multidecadal oscillation. Geophysical Research Letters, 33(17)

39. Kundzewicz ZW, Szwed M, Pińskwar I (2019) Climate variability and floods-A global review. Water 11(7):1399

40. Kusche J, Schmidt R, Petrovic S, Rietbroek R (2009) Decorrelated GRACE time-variable gravity solutions by GFZ, and their validation using a hydrological model. Journal of geodesy 83(10):903913

41. Lamb PJ, Peppler RA (1987) North Atlantic Oscillation: concept and an application. Bull Am Meteor Soc 68(10):1218-1225

42. Landerer FW, Volkov DL (2013) The anatomy of recent large sea level fluctuations in the Mediterranean Sea. Geophys Res Lett 40(3):553-557. https://doi.org/10.1002/grl.50140

43. Landerer FW, Wiese DN, Bentel K, Boening C, Watkins MM (2015) North Atlantic meridional overturning circulation variations from GRACE ocean bottom pressure anomalies. Geophys Res Lett 42:8114-8121. doi:10.1002/2015GL065730

44. Landerer FW, Flechtner FM, Save H, Webb FH, Bandikova T, Bertiger WI et al (2020) Extending the global mass change data record: GRACE Follow-On instrument and science data performance. Geophysical Research Letters, 47(12), e2020GL088306

45. Li C, Wettstein JJ (2012) Thermally driven and eddy-driven jet variability in reanalysis. J Clim 25(5):1587-1596 
46. Liau J-R, Chao BF (2017) Variation of Antarctic circumpolar current and its intensification in relation to the southern annular mode detected in the time-variable gravity signals by GRACE satellite. Earth Planets Space 69(1):93. https://doi.org/10.1186/s40623-017-0678-3

47. de Linage C, Kim H, Famiglietti JS, Yu J-Y (2013) Impact of Pacific and Atlantic sea surface temperatures on interannual and decadal variations of GRACE land water storage in tropical South America. Journal of Geophysical Research: Atmospheres, 118(19), 10,811 - 10,829. https://doi.org/10.1002/jgrd.50820

48. Litzow MA, Hunsicker ME, Bond NA, Burke BJ, Cunningham CJ, Gosselin JL et al (2020) The changing physical and ecological meanings of North Pacific Ocean climate indices. Proceedings of the National Academy of Sciences, 117(14), 7665-7671

49. Liu X, Feng X, Ciais P, Fu B (2020) Widespread decline in terrestrial water storage and its link to teleconnections across Asia and eastern Europe. Hydrol Earth Syst Sci 24(7):3663-3676. https://doi.org/10.5194/hess-24-3663-2020

50. Loomis BD, Rachlin KE, Luthcke SB (2019) Improved Earth oblateness rate reveals increased ice sheet losses and mass-driven sea level rise. Geophys Res Lett 46(12):6910-6917

51. Luo Z, Yao C, Li Q, Huang Z (2016) Terrestrial water storage changes over the Pearl River Basin from GRACE and connections with Pacific climate variability. Special Issue: Geodetic Geophysical Observations Applications Implications 7(3):171-179. https://doi.org/10.1016/j.geog.2016.04.008

52. Makowski JK, Chambers DP, Bonin JA (2015) Using ocean bottom pressure from the gravity recovery and climate experiment (GRACE) to estimate transport variability in the southern Indian Ocean. Journal of Geophysical Research: Oceans 120(6):4245-4259. https://doi.org/10.1002/2014JC010575

53. Mandea M, Panet I, Lesur V, de Viron O, Diament M, Mouël L, J.-L (2012) Recent changes of the Earth's core derived from satellite observations of magnetic and gravity fields. Proceedings of the National Academy of Sciences, 109(47), 19129. https://doi.org/10.1073/pnas.1207346109

54. Mandea M, Narteau C, Panet I, Le Mouël J-L (2015) Gravimetric and magnetic anomalies produced by dissolution-crystallization at the core-mantle boundary. Journal of Geophysical Research: Solid Earth 120(9):5983-6000. https://doi.org/10.1002/2015JB012048

55. Mantua NJ, Hare SR, Zhang Y, Wallace JM, Francis RC (1997) A Pacific interdecadal climate oscillation with impacts on salmon production. Bull Am Meteor Soc 78(6):1069-1080

56. Mariani M, Fletcher MS, Holz A, Nyman P (2016) ENSO controls interannual fire activity in southeast Australia. Geophys Res Lett 43(20):10-89

57. Marshall GJ (2003) Trends in the Southern Annular Mode from observations and reanalyses. J Clim 16(24):4134-4143

58. Matsuo K, Heki K (2012) Anomalous precipitation signatures of the Arctic Oscillation in the timevariable gravity field by GRACE. Geophys J Int 190(3):1495-1506. https://doi.org/10.1111/j.1365246X.2012.05588.x 
59. McPhaden MJ, Zebiak SE, Glantz MH (2006) ENSO as an integrating concept in earth science. Science 314(5806):1740-1745

60. Mohino E, Janicot S, Bader J (2011) Sahel rainfall and decadal to multi-decadal sea surface temperature variability. Clim Dyn 37(3-4):419-440

61. Mora C, Spirandelli D, Franklin EC, Lynham J, Kantar MB, Miles W et al (2018) Broad threat to humanity from cumulative climate hazards intensified by greenhouse gas emissions. Nature Climate Change 8(12):1062-1071

62. Morrow R, Ward ML, Hogg AM, Pasquet S (2010) Eddy response to Southern Ocean climate modes. Journal of Geophysical Research: Oceans 115:C10

63. Ndehedehe CE, Awange JL, Kuhn M, Agutu NO, Fukuda Y (2017) Climate teleconnections influence on West Africa's terrestrial water storage. Hydrol Process 31(18):3206-3224.

https://doi.org/10.1002/hyp.11237

64. Ndehedehe CE, Ferreira VG (2020) Identifying the footprints of global climate modes in time-variable gravity hydrological signals. Clim Change 159(4):481-502. https://doi.org/10.1007/s10584-01902588-2

65. Newman M, Alexander MA, Ault TR, Cobb KM, Deser C, Di Lorenzo E et al (2016) The Pacific decadal oscillation, revisited. J Clim 29(12):4399-4427

66. Ni S, Chen J, Wilson CR, Li J, Hu X, Fu R (2018) Global terrestrial water storage changes and connections to ENSO events. Surv Geophys 39(1):1-22

67. Paolo FS, Padman L, Fricker HA, Adusumilli S, Howard S, Siegfried MR (2018) Response of Pacificsector Antarctic ice shelves to the El Niño/Southern Oscillation. Nat Geosci 11(2):121-126. https://doi.org/10.1038/s41561-017-0033-0

68. Peltier R, Argus W, D. F., \& Drummond R (2018) Comment on "An assessment of the ICE-6G_C (VM5a) glacial isostatic adjustment model" by Purcell et al. Journal of Geophysical Research: Solid Earth 123(2):2019-2028

69. Peralta-Ferriz C, Morison JH, Wallace JM, Bonin JA, Zhang J (2014) Arctic Ocean Circulation Patterns Revealed by GRACE. J Clim 27(4):1445-1468. https://doi.org/10.1175/JCLI-D-13-00013.1

70. Peralta-Ferriz C, Morison JH, Wallace JM (2016) Proxy representation of Arctic ocean bottom pressure variability: Bridging gaps in GRACE observations. Geophys Res Lett 43(17):9183-9191

71. Petrick C, Dobslaw H, Bergmann-Wolf I, Schön N, Matthes K, Thomas M (2014) Low-frequency ocean bottom pressure variations in the North $\mathrm{P}$ acific in response to time-variable surface winds. Journal of Geophysical Research: Oceans 119(8):5190-5202

72. Pfeffer J, Tregoning P, Purcell A, Sambridge M (2018) Multitechnique Assessment of the Interannual to Multidecadal Variability in Steric Sea Levels: A Comparative Analysis of Climate Mode Fingerprints. J Clim 31(18):7583-7597. https://doi.org/10.1175/JCLI-D-17-0679.1

73. Phillips T, Nerem RS, Fox-Kemper B, Famiglietti JS, Rajagopalan B (2012) The influence of ENSO on global terrestrial water storage using GRACE. Geophys Res Lett, 39(16).

https://doi.org/10.1029/2012GL052495

Page 22/32 
74. Piecuch CG, Ponte RM (2011) Mechanisms of interannual steric sea level variability. Geophys Res Lett, 38(15). https://doi.org/10.1029/2011GL048440

75. Piecuch CG, Quinn KJ, Ponte RM (2013) Satellite-derived interannual ocean bottom pressure variability and its relation to sea level. Geophys Res Lett 40(12):3106-3110. https://doi.org/10.1002/grl.50549

76. Press WH, Rybicki GB (1989) Fast algorithm for spectral analysis of unevenly sampled data. Astrophys J 338:277-280

77. Riegger J, Tourian MJ, Devaraju B, Sneeuw N (2012) Analysis of grace uncertainties by hydrological and hydro-meteorological observations. Mass Transport Mass Distribution in the System Earth 5960:16-27. https://doi.org/10.1016/j.jog.2012.02.001

78. Rodell M, Houser PR, Jambor U, Gottschalck J, Mitchell K, Meng C-J et al (2004) The Global Land Data Assimilation System. Bull Am Meteor Soc 85(3):381-394. https://doi.org/10.1175/BAMS-85-3381

79. Rodell M, Famiglietti JS, Wiese DN, Reager JT, Beaudoing HK, Landerer FW, Lo M-H (2018) Emerging trends in global freshwater availability. Nature 557(7707):651-659. https://doi.org/10.1038/s41586018-0123-1

80. Saji NH, Goswami BN, Vinayachandran PN, Yamagata T (1999) A dipole mode in the tropical Indian Ocean. Nature 401(6751):360-363

81. Santoso A, Mcphaden MJ, Cai W (2017) The defining characteristics of ENSO extremes and the strong 2015/2016 El Niño. Rev Geophys 55(4):1079-1129

82. Save H, Bettadpur S, Tapley BD (2016) High-resolution CSR GRACE RL05 mascons. Journal of Geophysical Research: Solid Earth 121(10):7547-7569

83. Scanlon BR, Zhang Z, Save H, Wiese DN, Landerer FW, Long D et al (2016) Global evaluation of new GRACE mascon products for hydrologic applications. Water Resour Res 52(12):9412-9429. https://doi.org/10.1002/2016WR019494

84. Seneviratne S, Nicholls N, Easterling D, Goodess C, Kanae S, Kossin J et al (2012) Changes in climate extremes and their impacts on the natural physical environment

85. Stevens-Rumann CS, Kemp KB, Higuera PE, Harvey BJ, Rother MT, Donato DC et al (2018) Evidence for declining forest resilience to wildfires under climate change. Ecol Lett 21(2):243-252

86. Sun Y, Riva R, Ditmar P (2016) Optimizing estimates of annual variations and trends in geocenter motion and J2 from a combination of GRACE data and geophysical models. Journal of Geophysical Research: Solid Earth 121(11):8352-8370

87. Swenson S, Chambers D, Wahr J (2008) Estimating geocenter variations from a combination of GRACE and ocean model output. Journal of Geophysical Research: Solid Earth 113:B8

88. Tapley BD, Bettadpur S, Watkins M, Reigber C (2004) The gravity recovery and climate experiment: Mission overview and early results. Geophysical Research Letters, 31(9) 
89. Tapley BD, Watkins MM, Flechtner F, Reigber C, Bettadpur S, Rodell M et al (2019) Contributions of GRACE to understanding climate change. Nature Climate Change 9(5):358-369

90. Tang L, Li J, Chen J, Wang S-Y, Wang R, Hu X (2020) Seismic Impact of Large Earthquakes on Estimating Global Mean Ocean Mass Change from GRACE. Remote Sens 12(6):935. https://doi.org/10.3390/rs12060935

91. Thomas BF, Famiglietti JS, Landerer FW, Wiese DN, Molotch NP, Argus DF (2017) GRACE groundwater drought index: Evaluation of California Central Valley groundwater drought. Remote Sens Environ 198:384-392

92. Thompson DW, Solomon S (2002) Interpretation of recent Southern Hemisphere climate change. Science 296(5569):895-899

93. Tibshirani R (1996) Regression Shrinkage and Selection Via the Lasso. J Roy Stat Soc B 58(1):267288. https://doi.org/10.1111/j.2517-6161.1996.tb02080.x

94. Turco M, Llasat M-C, von Hardenberg J, Provenzale A (2014) Climate change impacts on wildfires in a Mediterranean environment. Clim Change 125(3):369-380

95. VanderPlas J, Connolly A, Ivezic Z, Gray A (2012) Introduction to astroML: Machine learning for astrophysics. Proceedings of the Conference on Intelligent Data Understanding (2012)

96. VanderPlas J, Ivezic Z (2015) Periodograms for Multiband Astronomical Time Series. ApJ 812.1:18 (2015)

97. VanderPlas J. Understanding the Lomb-Scargle Periodogram ApJS 236.1:16 (2018) https://ui.adsabs.harvard.edu/abs/2018ApJS..236... V

98. Vissa NK, Anandh PC, Behera MM, Mishra S (2019) ENSO-induced groundwater changes in India derived from GRACE and GLDAS. J Earth Syst Sci 128(5):115. https://doi.org/10.1007/s12040-019$1148-z$

99. Wang G, Cai W (2020) Two-year consecutive concurrences of positive Indian Ocean Dipole and Central Pacific El Niño preconditioned the 2019/2020 Australian “black summer” bushfires. Geoscience Letters 7(1):1-9

100. Watkins MM, Wiese DN, Yuan D-N, Boening C, Landerer FW (2015) Improved methods for observing Earth's time variable mass distribution with GRACE using spherical cap mascons. Journal of Geophysical Research: Solid Earth 120(4):2648-2671

101. Wessel P, Smith WHF (1996) A global, self-consistent, hierarchical, high-resolution shoreline database. Journal of Geophysical Research: Solid Earth 101(B4):8741-8743. https://doi.org/10.1029/96JB00104

102. Wiese DN, Landerer FW, Watkins MM (2016) Quantifying and reducing leakage errors in the JPL RL05M GRACE mascon solution. Water Resour Res 52(9):7490-7502. https:// doi.org/10.1002/2016WR019344

103. Wolter K, Timlin MS (1998) Measuring the strength of ENSO events: How does 1997/98 rank? Weather 53(9):315-324 
104. Woollings T, Blackburn M (2012) The North Atlantic jet stream under climate change and its relation to the NAO and EA patterns. J Clim 25(3):886-902

105. Xie Z, Huete A, Cleverly J, Phinn S, McDonald-Madden E, Cao Y, Qin F (2019) Multi-climate mode interactions drive hydrological and vegetation responses to hydroclimatic extremes in Australia. Remote Sens Environ 231:111270. https://doi.org/10.1016/j.rse.2019.111270

106. Yang J, Liu Q, Xie S-P, Liu Z, Wu L (2007) Impact of the Indian Ocean SST basin mode on the Asian summer monsoon. Geophys Res Lett, 34(2). https://doi.org/10.1029/2006GL028571

107. Ye X, Zhang W, Luo M (2016) The North Pacific Gyre Oscillation and East Asian summer precipitation. Atmospheric Science Letters 17(10):531-537. https://doi.org/10.1002/asl.688

108. Yoon J-H, Wang SS, Gillies RR, Kravitz B, Hipps L, Rasch PJ (2015) Increasing water cycle extremes in California and in relation to ENSO cycle under global warming. Nat Commun 6(1):1-6

109. Zampieri M, Toreti A, Schindler A, Scoccimarro E, Gualdi S (2017) Atlantic multi-decadal oscillation influence on weather regimes over Europe and the Mediterranean in spring and summer. Global Planet Change 151:92-100

110. Zhang R, Delworth TL (2006) Impact of Atlantic multidecadal oscillations on India/Sahel rainfall and Atlantic hurricanes. Geophysical Research Letters, 33(17)

111. Zhang W, Leung Y, Min J (2013) North Pacific Gyre Oscillation and the occurrence of western North Pacific tropical cyclones. Geophys Res Lett 40(19):5205-5211. https://doi.org/10.1002/grl.50955

112. Zhang X, Church JA (2012) Sea level trends, interannual and decadal variability in the Pacific Ocean. Geophys Res Lett, 39(21). https://doi.org/10.1029/2012GL053240

113. Zhang Z, Chao BF, Chen J, Wilson CR (2015) Terrestrial water storage anomalies of Yangtze River Basin droughts observed by GRACE and connections with ENSO. Global Planet Change 126:35-45. https://doi.org/10.1016/j.gloplacha.2015.01.002

114. Zhou S, Miller AJ, Wang J, Angell JK (2001) Trends of NAO and AO and their associations with stratospheric processes. Geophys Res Lett 28(21):4107-4110

\section{Figures}




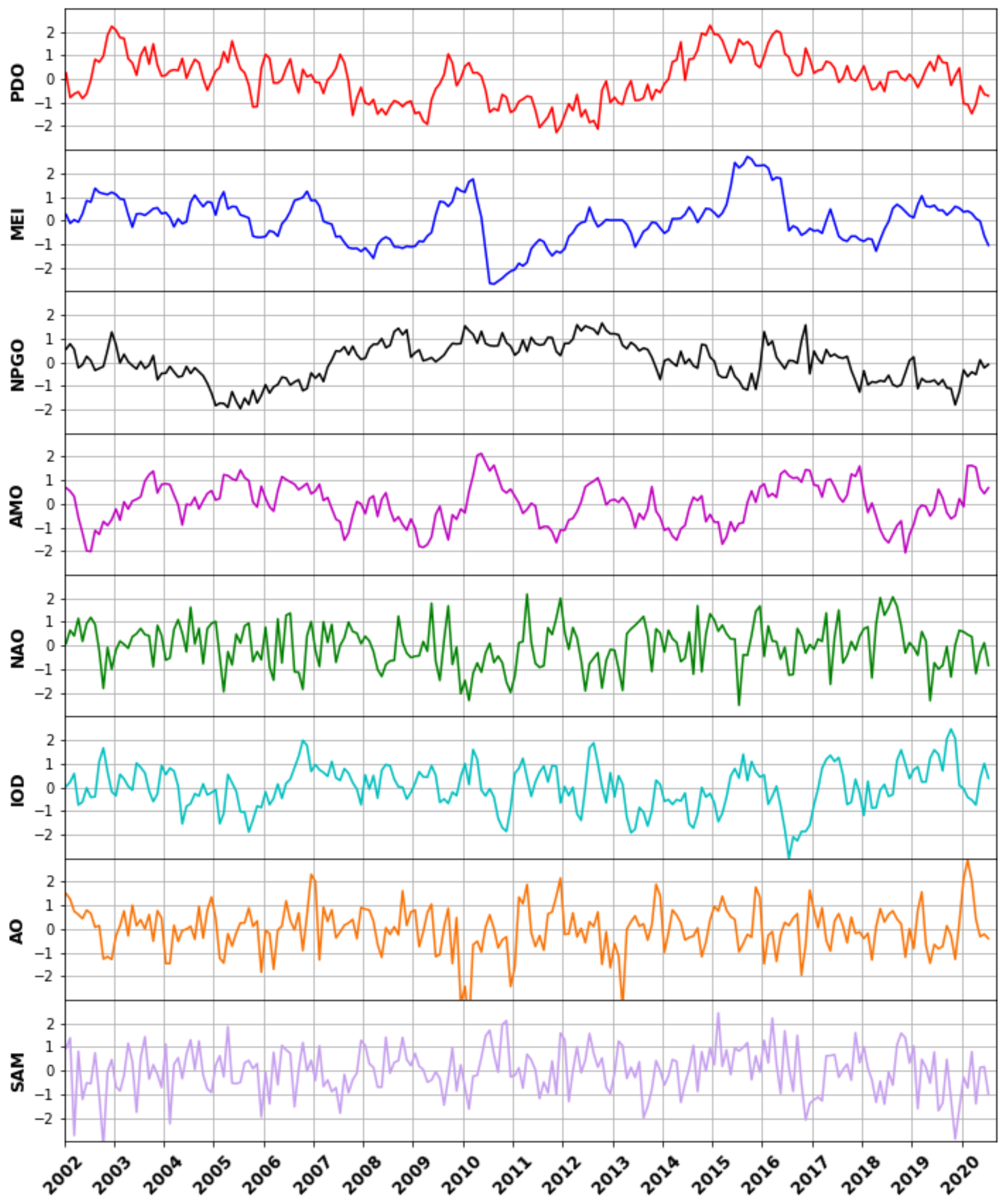

Figure 1

Normalized climate indices during the 2002 - 2020 time-period with a linear trend, annual sinusoid and semi-annual sinusoid removed 


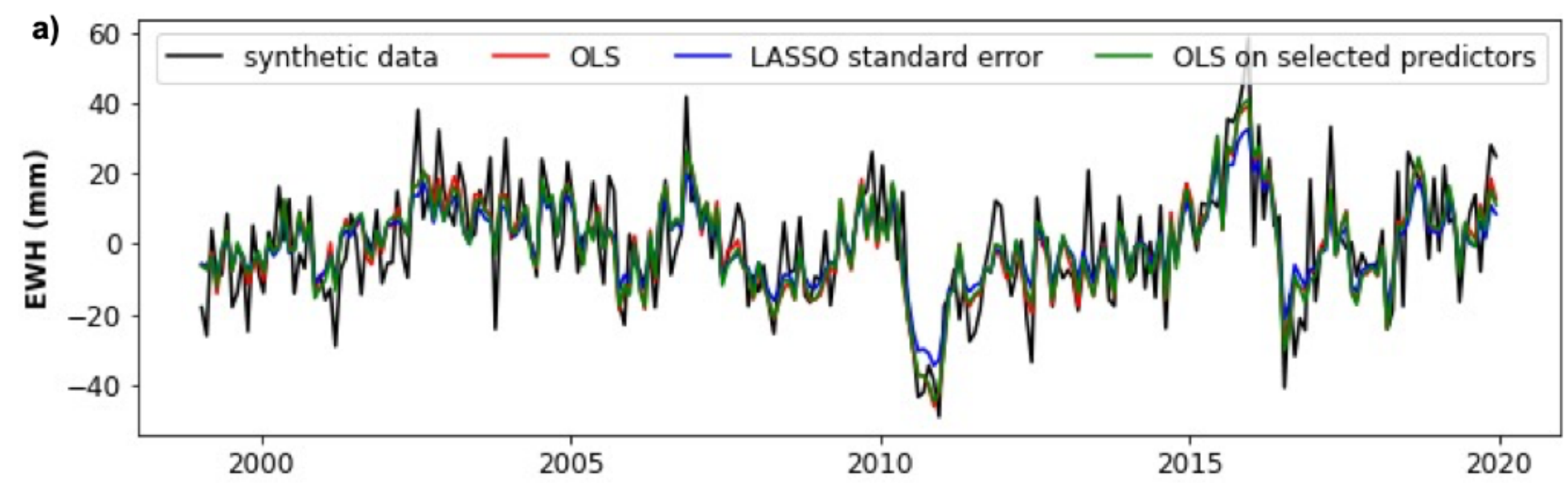

b)
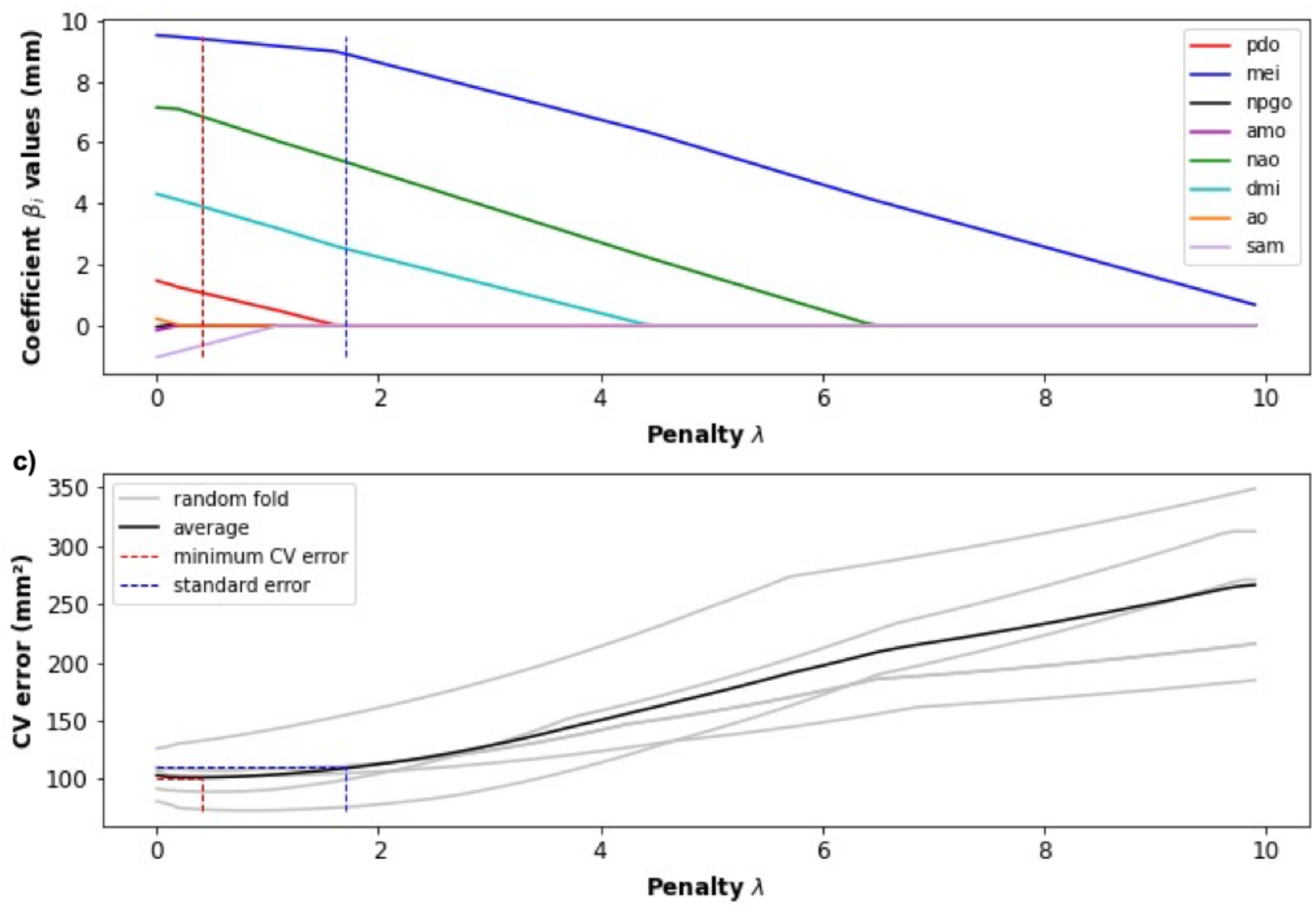

Figure 2

Synthetic test of the climate modes inversion procedure. a) Comparison of synthetic data with the results of an ordinary least squares (OLS) inversion, a LASSO regression minimizing the standard error and an OLS inversion carried out on selected predictors only. b) Evolution of estimated coefficients $\beta i$ with the penalty $\lambda$. The red (blue) dotted line symbolizes the penalty value minimizing the average CV error (the standard CV error). Synthetic values for $\beta$ i coefficients are 10, 7.5 and 5 for MEI, NAO and DMI and zero 
for all the other coefficients. c) Evolution of the CV error with the penalty value $\lambda$. The grey lines show the CV error for individual folds. The bold black line shows the average CV error. The red (blue) dotted line shows the penalty corresponding to the minimum CV error (standard CV error).
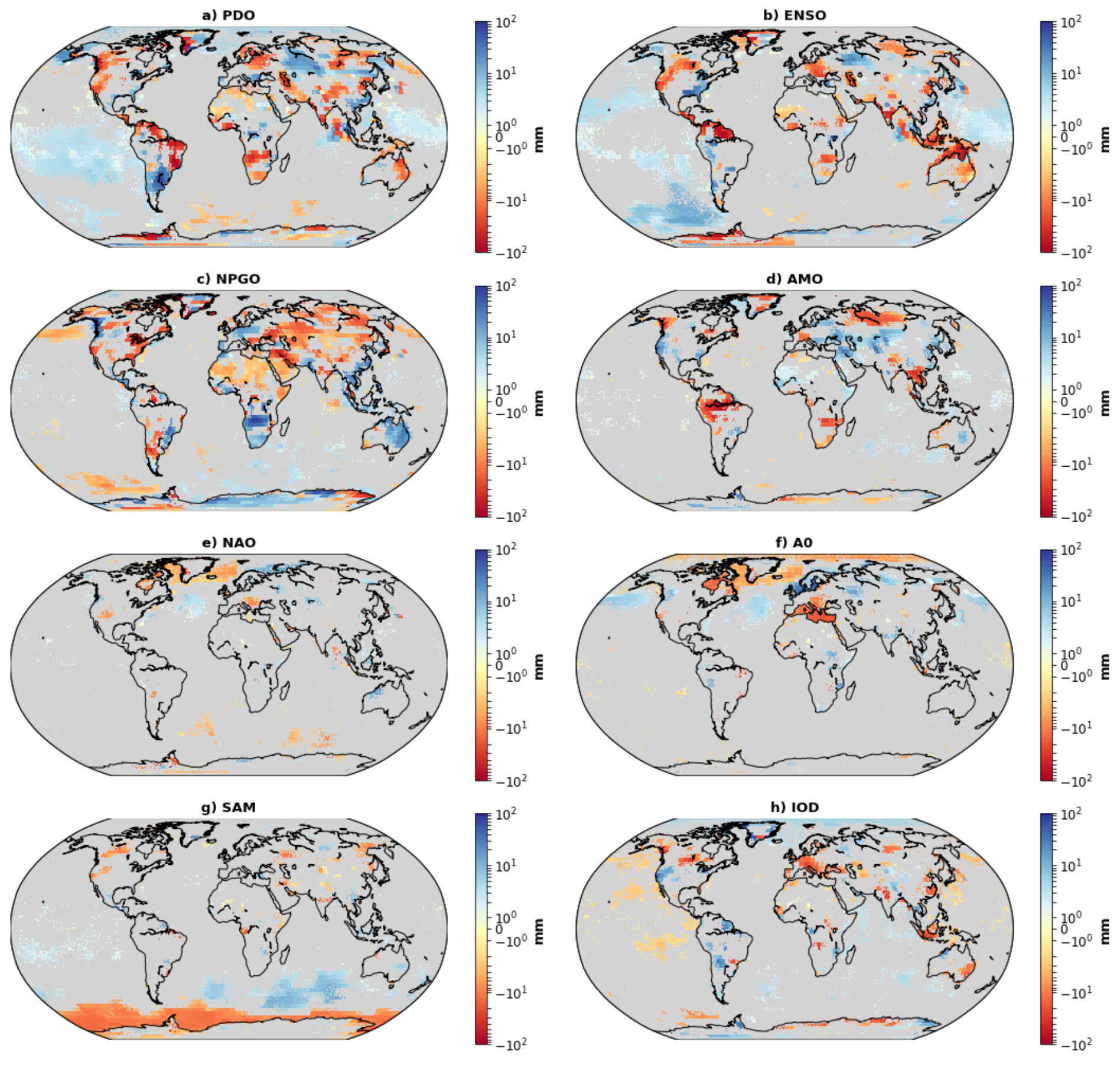

Figure 3

Climate mode fingerprints resulting from the inversion of eight climate indices for the locally detrended and deseasoned JPL solutions. Null values are plotted in a light gray color. 

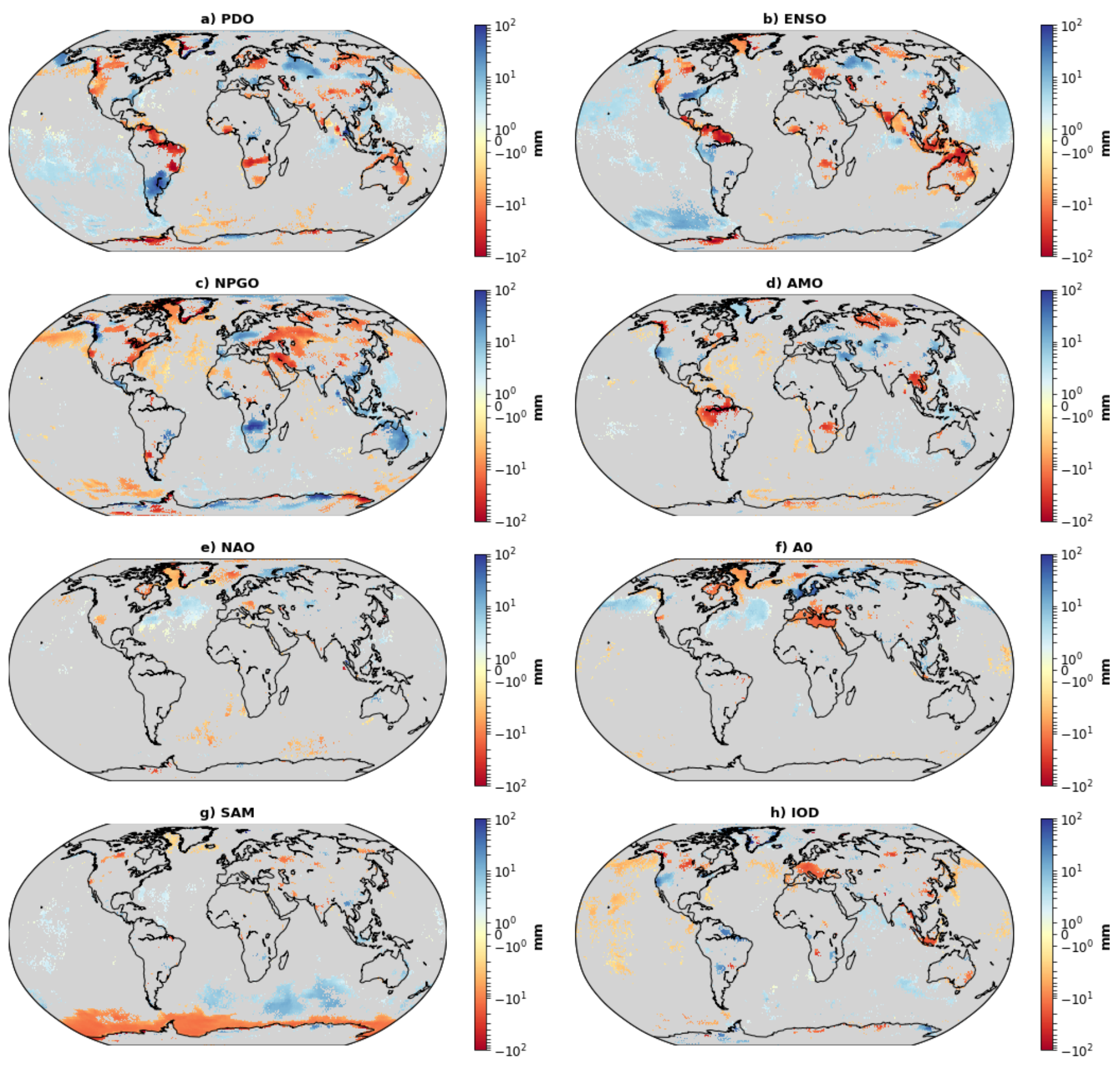

Figure 4

Climate mode fingerprints resulting from the inversion of eight climate indices for the locally detrended and deseasoned CSR solutions. Null values are plotted with a light gray color. 
a) Lo-norm CSR
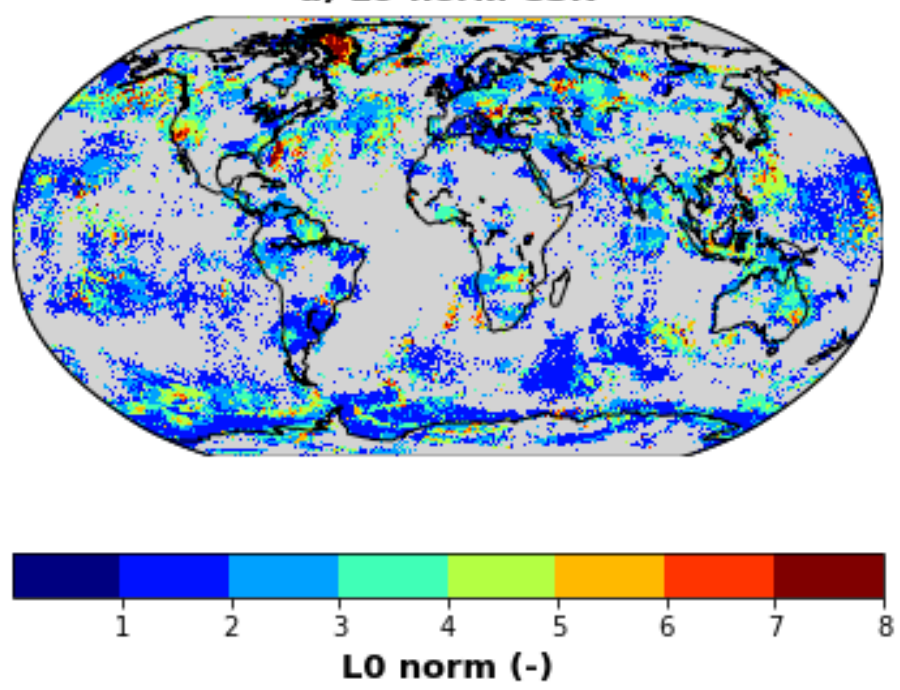

c) Penalty CSR
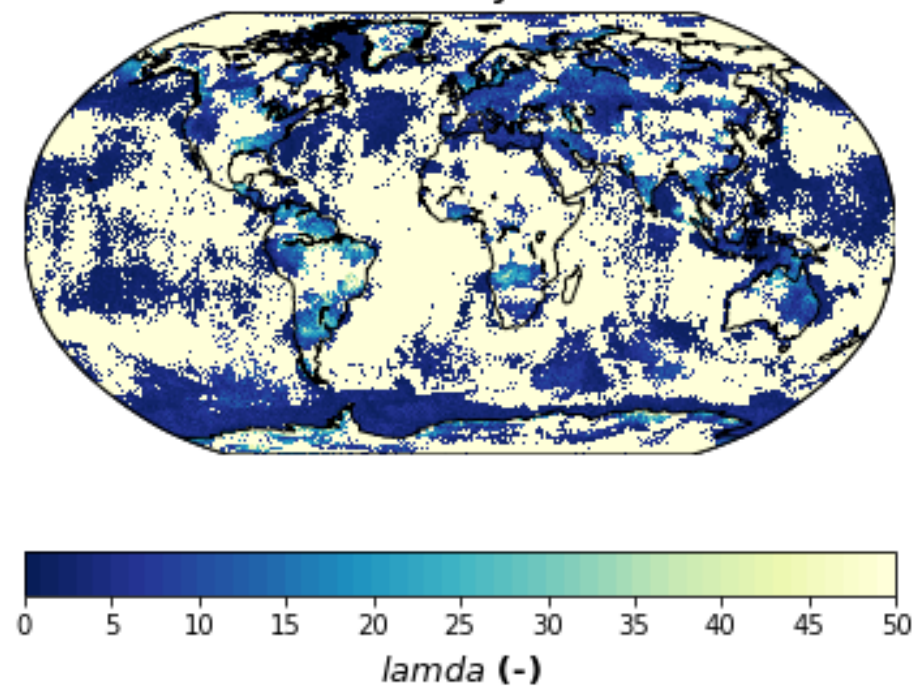

b) Lo-norm JPL
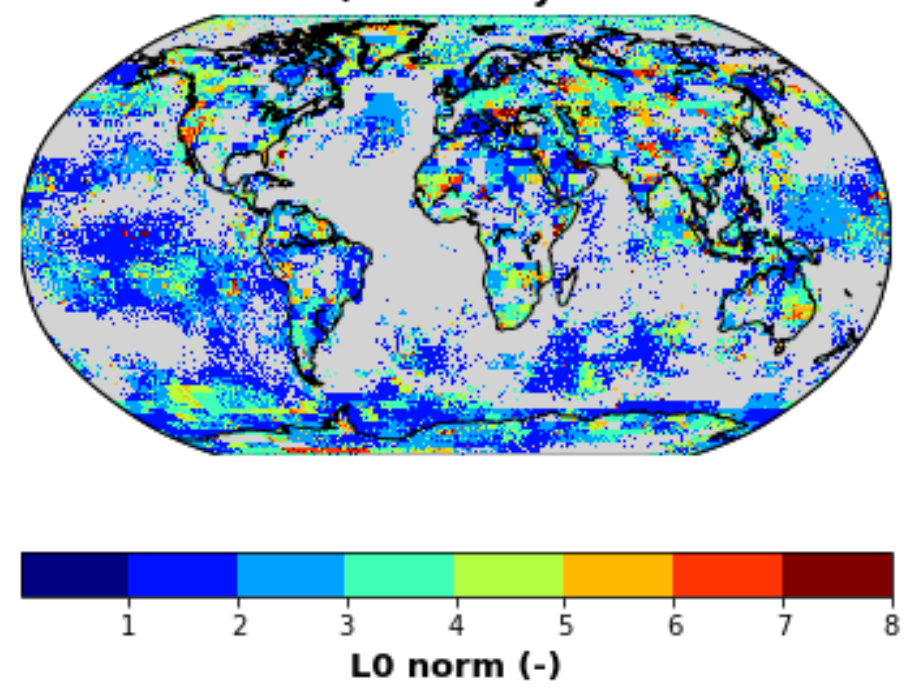

d) Penalty JPL
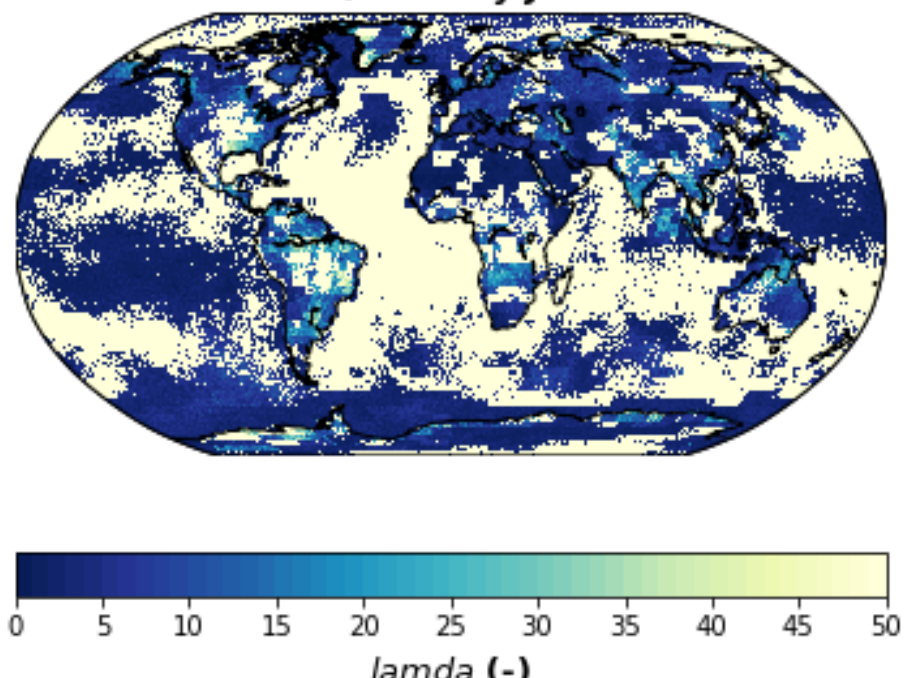

Figure 5

Parameters of the LASSO regression. ( $a \& b)$ LO-norm of the vector of the regression coefficients $\beta \mathrm{i}$. The light gray color indicates null values of the L0-norm. The LO-norm gives the number of climate indices needed in the regression model to reproduce at best the interannual variability of water mass redistributions estimated with the CSR (a) and JPL (b) mascon solutions. (c \& d) Penalty $\lambda$ minimizing the standard error of a 5 -fold cross validation for the CSR (c) and JPL (b) mascon solutions. The degree of shrinkage of the regression coefficients $\beta \mathrm{i}$ increases with $\lambda$. 
a) RMS of detrended deseasoned CSR solutions

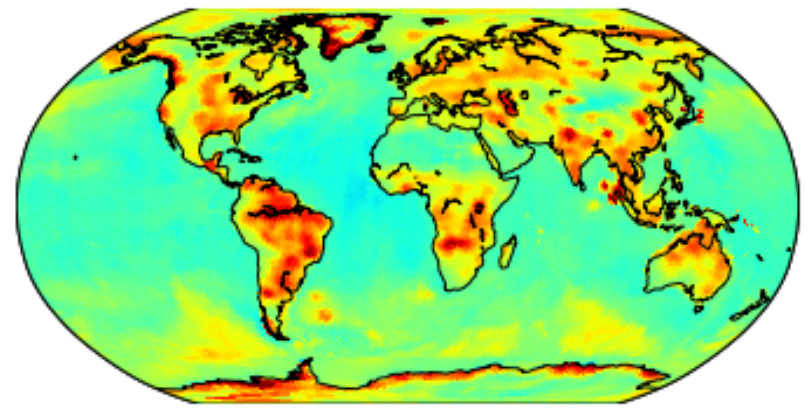

b) RMS of detrended deseasoned JPL solutions
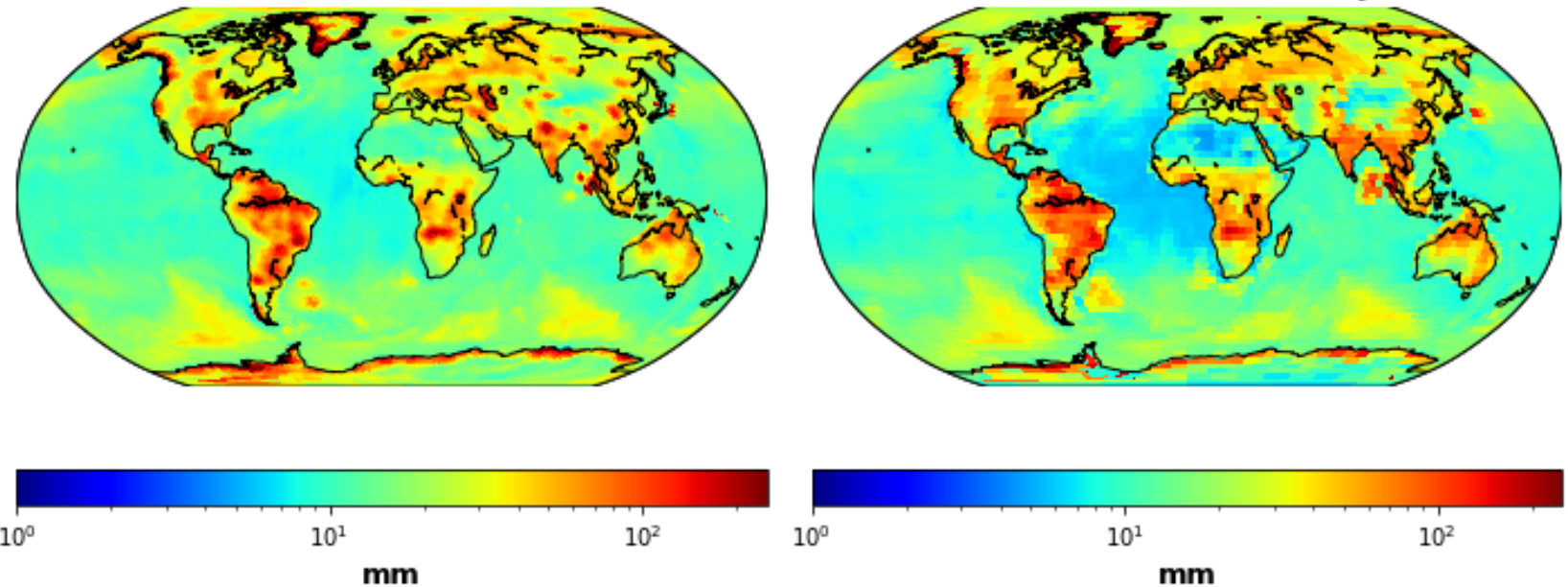

c) RMS climate modes predictions for the CSR
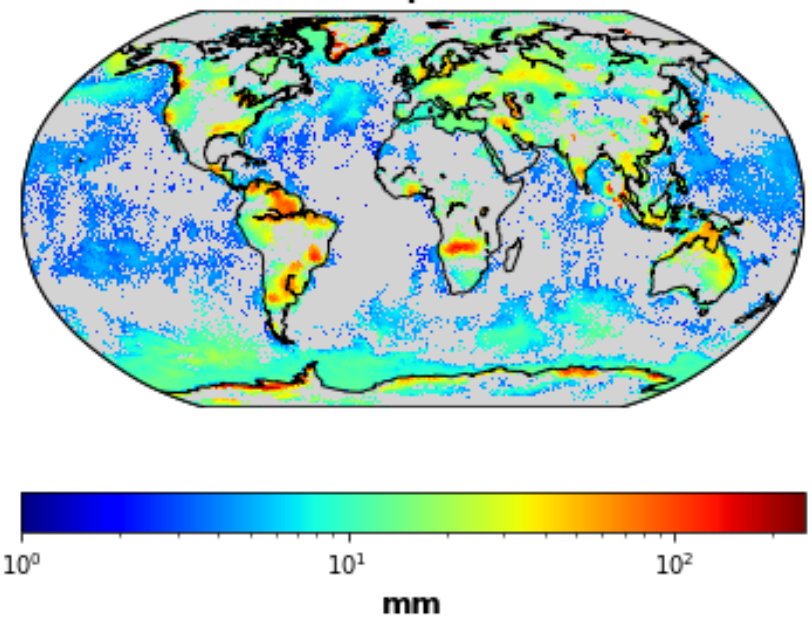

e) $R^{2}$ values for the CSR
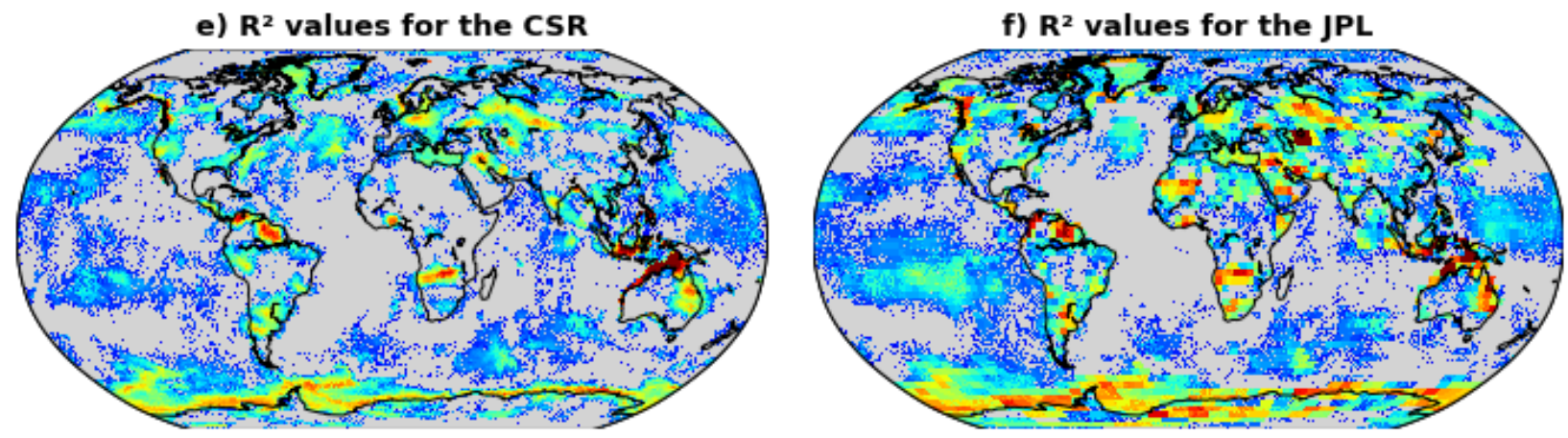

d) RMS climate modes predictions for the JPL
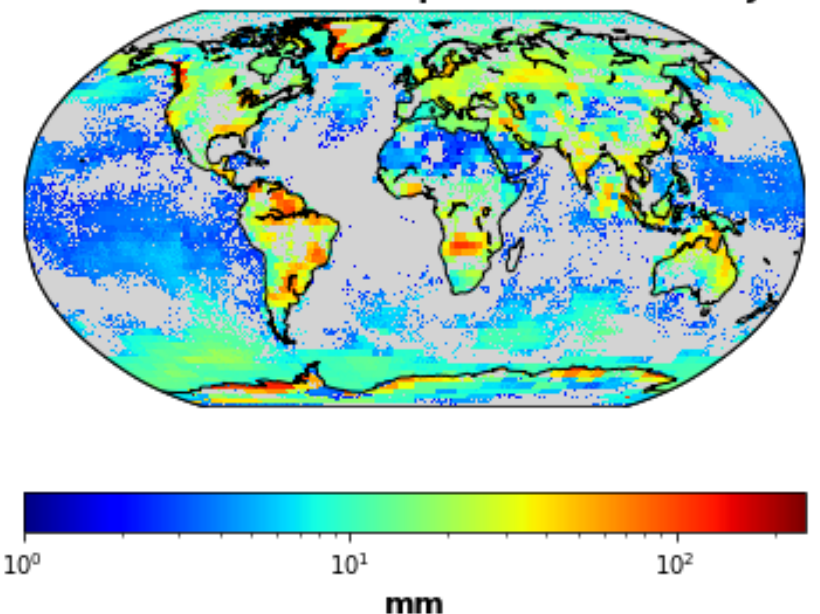

f) $R^{2}$ values for the JPL

0.

0.1

0.2

0.3

0.5

Figure 6

Performance of the regression model: $(a, b)$ Amplitude of the interannual signals the for the CSR and JPL mascons solutions respectively; (c,d) Amplitude of the climate modes predictions for the CSR and JPL solutions respectively; (e,f) Determination coefficients between the climate modes predictions and the locally detrended and deseasoned CSR and JPL solutions respectively 


\section{Supplementary Files}

This is a list of supplementary files associated with this preprint. Click to download.

- Supplementaryfinal.pdf 